UNIVERSIDADE DE SÃO PAULO

ESCOLA DE ENFERMAGEM

FRANCIELE DO NASCIMENTO SANTOS

EFEITO RENOPROTETOR DA ESTATINA EM MODELO EXPERIMENTAL DE LESÃO RENAL AGUDA INDUZIDA POR SEPSE

São Paulo

2013 
FRANCIELE DO NASCIMENTO SANTOS

\section{EFEITO RENOPROTETOR DA ESTATINA EM MODELO EXPERIMENTAL DE LESÃO RENAL AGUDA INDUZIDA POR SEPSE}

Dissertação apresentada ao Programa de PósGraduação em Enfermagem na Saúde do Adulto da Escola de Enfermagem da Universidade de São Paulo para obtenção do Título de Mestre em Ciências.

Área de Concentração:

Enfermagem na Saúde do Adulto

Linha de pesquisa:

Tecnologia na Saúde do Adulto

Orientadora:

Prof $^{a}{ }^{-} r^{a}$ Maria de Fatima Fernandes Vattimo

São Paulo

2013 
AUTORIZO A REPRODUÇÃO E DIVULGAÇÃO TOTAL OU PARCIAL DESTE TRABALHO, POR QUALQUER MEIO CONVENCIONAL OU ELETRÔNICO, PARA FINS DE ESTUDO E PESQUISA, DESDE QUE CITADA A FONTE.

Assinatura:

Data:

\section{Catalogação na Publicação (CIP) \\ Biblioteca "Wanda de Aguiar Horta"}

Escola de Enfermagem da Universidade de São Paulo

Santos, Franciele do Nascimento

Efeito renoprotetor da estatina em modelo experimental de lesão renal aguda induzida por sepse / Franciele do Nascimento Santos. - São Paulo, 2013.

$65 \mathrm{p}$.

Dissertação (Mestrado) - Escola de Enfermagem da Universidade de São Paulo.

Orientadora: Profa. Dra. Maria de Fatima Fernandes Vattimo Área de concentração: Enfermagem na Saúde do Adulto

1. Sepse 2. Sinvastatina 3. Antioxidantes I Título 


\section{FOLHA DE APROVAÇÃO}

Nome: Franciele do Nascimento Santos.

Título: Efeito renoprotetor da estatina em modelo experimental de lesão renal aguda induzida por sepse.

Dissertação apresentada ao Programa de Pós-Graduação em Enfermagem na Saúde do Adulto da Escola de Enfermagem da Universidade de São Paulo para obtenção do Título de Mestre em Ciências.

Aprovado em:

\section{Banca Examinadora}

Prof. Dr.

Instituição:

Julgamento:

Assinatura:

Prof. Dr.

Instituição:

Julgamento:

Assinatura:

Prof. Dr.

Instituição:

Julgamento:

Assinatura: 
Dedicatória

Aos meus avós, Antônio e Clarice, exemplos de sabedoria e valores, presença doce de amor, cuidado e incentivo infinito durante toda minha vida.

Aos meus pais, Claudiomar e Eliana, pelo amor e motivação constante, por acreditarem em meus sonhos e não medirem esforços para torná-los realidade. A minha mãe de coração, Irinéia, por todo amparo, compreensão, carinho e incentivo em todos os aspectos da minha vida.

As minhas irmãs, Sara, Maria Fernanda e Ana Clara, por toda graça e alegria que trazem aos meus dias.

Ao Luciano, presente de Deus, meu companheiro dedicado e fiel, que de forma especial me deu todo amor, atenção, compreensão e apoio durante esta etapa. 


\section{Agradecimentos Especiais}

A DEUS, que se faz presente em minha vida, me fortalecendo e me iluminando a cada dia.

A minha orientadora Prof" Dra Maria de Fatima Fernandes Vattimo, pela confiança, apoio, ensinamentos e conselhos durante todo esse tempo de convivência. Com todo respeito, carinho e admiração, Ihe agradeço: Muito obrigada por tudo.

A Dra Mirian Watanabe, pela ajuda e incentivo constantes em todas as etapas deste trabalho. Agradeço também, pela convivência construtiva e agradável, por todo conhecimento transmitido, sugestôes e colaboração nos experimentos.

A Dra Luciana Barros de Moura Neiva, pelas contribuiçôes no exame de qualificação. Suas sugestôes foram de grande valia para a realização deste trabalho.

A Dra Cassiane Dezoti da Fonseca, pela inestimável colaboração ao me ensinar todas as rotinas do LEMA, pelo carinho, ajuda e incentivo durante todo o Mestrado.

A' Neusa da Silva Oliveira, companhia acolhedora e maternal. Obrigada pelo carinho e cuidado durante esses três anos de convivio.

A Mestre Carolina Ferreira Pinto, pela orientação para padronizar o modelo de sepse.

As alunas e amigas, Mariana Hayashi de Mendonça e Sheila Marques Fernandes, pela parceria, convivio agradável e ajuda durante o desenvolvimento desse estudo.

Aos pesquisadores do LEMA, Cecilia Ide Ogata, Daniel Malisani Martins, Espedito Ladier do Nascimento, Fábio dos Santos Schlotffeldt, Juliana Guareschi dos Santos e Silvane Munhoz Rocha, por todos os momentos de aprendizado que contribuiram para minha formação.

Aos meus avós maternos, Bento (in memorian) e Izaldira, por todo amor, atenção e ensinamentos desprendidos durante toda minha vida. 
As amigas, Alessandra Cainelli, Aline Cainelli e Danusa Preve, que se tornaram minhas irmãs. Agradeço por todos os momentos vividos, por toda amizade, gentileza, acolhimento, carinho e cumplicidade.

Aos amigos, Cleverton Teixeira, Daniele Alves, Franciele Cortes e Laura Suemy Morikawa, que mesmo distantes fisicamente, sempre estiveram ao meu lado, me incentivando, torcendo e vibrando por minhas conquistas.

Agradeço a todos os meus familiares e amigos que torcem por mim a distância. Obrigada pelas oraçôes, pela compreensão e carinho.

Aos amigos bolsistas da pós-graduação, em especial Alda Graciele e Janaina Soares pela convivência alegre e motivadora no decorrer desses trếs anos na EEUSP.

A todos os funcionários da EEUSP, pela colaboração direta ou indireta na realização deste trabalho. 
Santos FN. Efeito renoprotetor da estatina em modelo experimental de lesão renal aguda induzida por sepse. [dissertação]. São Paulo: Escola de Enfermagem da Universidade de São Paulo; 2013.

\section{RESUMO}

A sepse é uma das síndromes clínicas mais frequentes em unidades de terapia intensiva (UTI), enquanto que a lesão renal aguda (LRA) é uma complicação comum da disfunção de múltiplos órgãos (DMOs) causada pela sepse. Os mecanismos fisiopatológicos envolvidos na LRA por sepse são a hipoperfusão glomerular, as alterações microvasculares e a liberação de espécies reativas de oxigênio (EROs). Nesse contexto, o efeito antioxidante da estatina pode ser considerado. O objetivo desse estudo foi investigar a repercussão da sepse e o efeito da sinvastatina sobre a função renal dos ratos. Foram utilizados ratos Wistar, adultos e machos, pesando entre 250-300 gramas. Os animais foram distribuídos nos grupos: SHAM (controle da sepse); SHAM + Estatina (0,5 $\mathrm{mg} / \mathrm{kg}$ de sinvastatina por gavagem, uma vez ao dia, durante cinco dias); Sepse (laparatomia para ligadura e punção de cécum - LPC); Sepse + Estatina (tratamento com sinvastatina e LPC). Foram avaliados os parâmetros fisiológicos (peso corporal, temperatura corporal e glicemia capilar), a presença de micro-organismos no líquido peritoneal, a função renal (clearance de creatinina, método Jaffé), os metabólitos oxidativos (peróxidos urinários - FOX2 e substâncias reativas com o ácido tiobarbitúrico - TBARS), a gravidade da LRA e a sobrevida dos animais. Os resultados mostraram que os animais com sepse apresentaram hipertermia, hiperglicemia e crescimento microbiano em cultura do líquido peritoneal, declínio do clearance de creatinina com elevação dos níveis de peróxidos urinários e TBARS. O grupo Sepse foi classificado com LRA de maior gravidade e alta taxa de mortalidade, enquanto que o grupo que recebeu sinvastatina apresentou aumento da taxa de filtração glomerular (TFG), com atenuação da geração dos metabólitos oxidativos, associados à menor gravidade da LRA e redução da taxa de mortalidade. Os achados dessa investigação confirmam o desenvolvimento de LRA grave secundária a sepse e evidenciam a renoproteção com princípio antioxidante da sinvastatina.

Palavras-chave: Sepse, Lesão Renal Aguda, Sinvastatina, Antioxidantes. 
Santos FN. Renoprotective effect of statins in experimental model of sepsis induced acute kidney injury. [dissertation]. São Paulo: Escola de Enfermagem da Universidade de São Paulo; 2013.

\section{ABSTRACT}

Sepsis is one of the most frequent clinical syndromes in the intensive care unit (ICU), while acute kidney injury (AKI) is a common complication of multiple organ dysfunction (MODs) caused by sepsis. The pathophysiological mechanisms involved in the sepsis AKI are glomerular hypoperfusion, microvascular changes and release of reactive oxygen species (ROS). In this context, the antioxidant effect of the statin may be considered. The aim of this study was to investigate the impact of sepsis and the effect of simvastatin on renal function in rats. Wistar, adult, male rats weighing between 250-300 grams. The protocol of sepsis, consisted in a laparotomy and induced abdominal sepsis by cecal ligation and puncture (CLP). The animals were divided in groups: SHAM (sepsis control), SHAM + Statin $(0.5 \mathrm{mg} / \mathrm{kg}$ of simvastatin by gavage, once daily for five days), Sepsis (laparotomy for cecal ligation and puncture CLP), Sepsis + Statin (simvastatin treatment and CLP). We evaluated physiological parameters (body weight, body temperature and capillary glycemia blood), the presence of microorganisms in the peritoneal fluid, renal function (creatinine clearance, Jaffe method), metabolites oxidative (urinary peroxides - FOX-2 and reactive substances to thiobarbituric acid - TBARS), the severity of $\mathrm{AKI}$ and the animals survival. Sepsis animals presented hyperthermia, hyperglycemia and microbial growth in culture of peritoneal fluid and creatinine clearance decrease with elevated levels of urinary peroxides and TBARS. The Sepsis group was classified as the most severe AKI and high mortality rate. The animals that received simvastatin showed improvement in physiological parameters, increased glomerular filtration rate (GFR) with attenuation of the generation of oxidative metabolites, associated with lower severity of $\mathrm{AKI}$ and reduced mortality. The findings of this investigation confirm the development of $\mathrm{AKI}$ secondary to sepsis and confirm the renoprotection with simvastatin associated to its antioxidant effect.

Keywords: Sepsis, Acute Kidney Injury, Simvastatin, Antioxidants. 


\section{LISTA DE ILUSTRAÇÕES}

Figura 1 - Ilustrações da gaiola metabólica........................................ 28

Figura 2 - Sequência cronológica do protocolo experimental................. 30

Figura 3 - Cultura do líquido peritoneal dos animais dos grupos SHAM e Sepse nos diferentes períodos...........................................

Gráfico 1- Estágios de gravidade de LRA dos grupos SHAM, SHAM + Estatina, Sepse e Sepse + Estatina.................................... 42

Gráfico 2 - Curva de sobrevida dos grupos SHAM, SHAM + Estatina, Sepse e Sepse + Estatina ............................................. 44

Quadro 1 - Classificação das culturas do líquido peritoneal dos grupos SHAM e Sepse nos diferentes períodos 


\section{LISTA DE TABELAS}

Tabela 1- Resultados referentes ao peso corporal dos grupos: SHAM, SHAM + Estatina, Sepse e Sepse + Estatina. São Paulo. 2013.

Tabela 2- Resultados referentes à temperatura corporal e glicemia capilar e dos grupos: SHAM, SHAM + Estatina, Sepse e Sepse + Estatina. São Paulo. 2013.

Tabela 3- Resultados referentes à função renal global dos grupos: SHAM, SHAM + Estatina, Sepse e Sepse + Estatina. São Paulo. 2013.

Tabela 4- Resultados referentes aos valores de peróxidos e TBARS urinários dos grupos: SHAM, SHAM + Estatina, Sepse e Sepse + Estatina. São Paulo. 2013. 40 


\section{LISTA DE ABREVIATURAS}

\begin{tabular}{|c|c|}
\hline AKIN & Acute Kidney Injury Network \\
\hline $\mathrm{BHT}$ & 2 [6]-di-ter-bu-til-p-cresol \\
\hline Clcr & clearance de creatinina \\
\hline $\mathrm{Cr}$ & creatinina \\
\hline CrU & creatinina urinária \\
\hline CIVD & coagulação intravascular disseminada \\
\hline DMOs & disfunção de múltiplos órgãos \\
\hline EROs & espécies reativas de oxigênio \\
\hline FOX-2 & método xilenol laranja versão-2 \\
\hline FSR & fluxo sanguíneo renal \\
\hline HMG-CoA & 3-hidroxi-3-metilglutaril coenzima $A$ \\
\hline $\mathrm{H}_{2} \mathrm{O}_{2}$ & peróxido de hidrogênio \\
\hline $\mathrm{H}_{2} \mathrm{SO}_{4}$ & ácido sulfúrico \\
\hline ICAM-1 & moléculas de adesão intercelular-1 \\
\hline IL-1 & interleucina-1 \\
\hline IL-6 & interleucina-6 \\
\hline iNOS & óxido nítrico sintase induzível \\
\hline ip & intraperitoneal \\
\hline LDL & colesterol lipídico de baixa densidade \\
\hline LPC & ligadura e punção do cécum \\
\hline LRA & lesão renal aguda \\
\hline
\end{tabular}




$\begin{array}{ll}\text { MDA } & \text { malondeldeídeo } \\ \text { MPC-1 } & \text { monócitos-1 } \\ \text { Na-K-ATPase } & \text { sódio-potássio-ATPase } \\ \text { NO } & \text { óxido nítrico } \\ \mathrm{O}_{2}{ }^{-} & \text {ânion superóxido } \\ \mathrm{OH}^{-} & \text {radical hidroxila } \\ \text { PAF } & \text { fator de agregação plaquetária } \\ \text { PCR } & \text { proteína-C reativa } \\ \text { RV } & \text { ressuscitação volêmica } \\ \text { SC } & \text { subcutânea } \\ \text { SOD } & \text { superóxido dismutase } \\ \text { TBARS } & \text { substâncias reativas com ácido tiobarbitúrico } \\ \text { TCA } & \text { ácido tricloroacético } \\ \text { TFG } & \text { taxa de filtração glomerular } \\ \text { TNF- } \alpha & \text { fator de necrose tumoral- } \alpha \\ \text { TNF- } \beta & \text { fator de transcrição nuclear- } \beta \\ \text { TSB } & \text { via oral } \\ \text { UTI } & \text { vo }\end{array}$




\section{LISTA DE SIGLAS}

CEUA Comitê de Ética em Uso de Animais

COBEA Colégio Brasileiro de Experimentação Animal

EEUSP Escola de Enfermagem da Universidade de São Paulo

FMUSP Faculdade de Medicina da Universidade de São Paulo

FSP-USP Faculdade de Saúde Pública-Universidade de São Paulo

LEMA Laboratório Experimental de Modelos Animais 


\section{LISTA DE SÍMBOLOS}

\begin{tabular}{|c|c|}
\hline$\mu l$ & microlitro \\
\hline$\mu \mathrm{M}$ & micromolar \\
\hline$\mu \mathrm{mol}$ & micromol \\
\hline$\stackrel{\circ}{\mathrm{C}}$ & graus Celsius \\
\hline $\mathrm{cm}$ & centímetro \\
\hline $\mathrm{dl}$ & decilitro \\
\hline $\mathrm{h}$ & hora \\
\hline $\mathrm{kg}$ & quilograma \\
\hline $\mathrm{mg}$ & miligrama \\
\hline $\min$ & minuto \\
\hline $\mathrm{ml}$ & mililitro \\
\hline $\mathrm{mm}$ & milímetro \\
\hline $\mathrm{mM}$ & milimolar \\
\hline $\mathrm{n}$ & número de animais estudados \\
\hline $\mathrm{nmol}$ & nanomolar \\
\hline$p$ & nível de significância \\
\hline rpm & rotações por minuto \\
\hline
\end{tabular}




\section{SUMÁRIO}

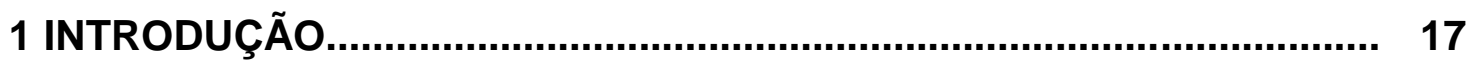

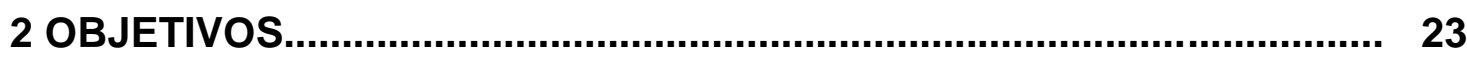

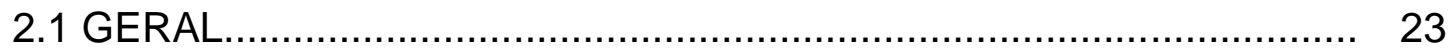

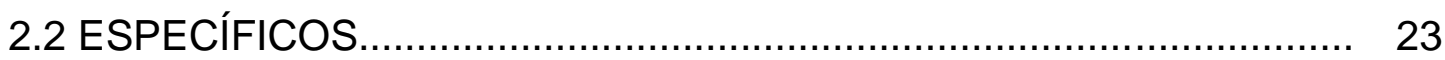

3 MATERIAIS E MÉTODOS.............................................................. 25

3.1 MATERIAIS .................................................................... 25

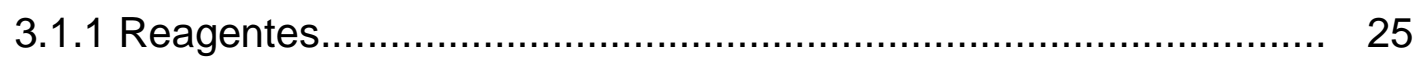

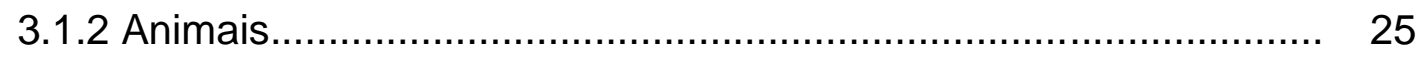

3.2 PROCEDIMENTOS ............................................................. 26

3.2.1 Modelo de LRA induzida por sepse.......................................... 26

3.2.2 Ressuscitação volêmica.......................................................... 27

3.2.3 Administração de estatina...................................................... 27

3.2.4 Apresentação dos grupos experimentais..................................... 27

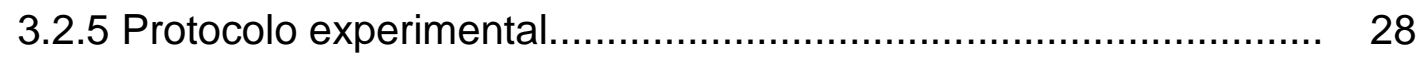

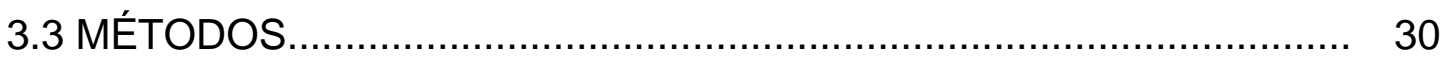

3.3.1 Função renal................................................................ 30

3.3.2 Metabólitos oxidativos.......................................................... 31

3.3.3 Gravidade da LRA e curva de sobrevida................................... 32

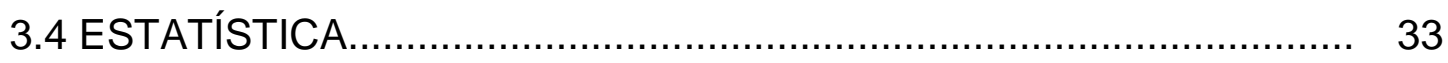

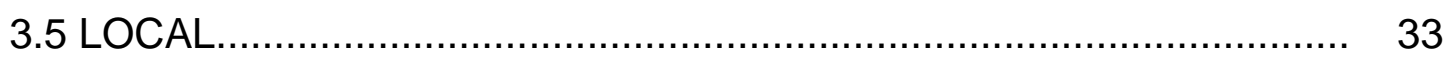

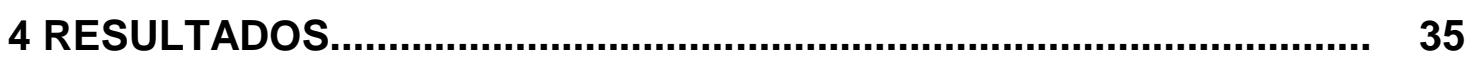

4.1 PARÂMETROS FISIOLÓGICOS ............................................. 35

4.1.1 Peso corporal................................................................... 35

4.1.2 Temperatura e glicemia capilar.................................................. 36

4.2 CULTURA DO LÍQUIDO PERITONEAL........................................... 37

4.3 FUNÇÃO RENAL.................................................................. 38

4.3.1 Clearance de creatinina................................................................. 38

4.4 METABÓLITOS OXIDATIVOS........................................................ 40

4.4.1 Peróxidos e TBARS urinários....................................................... 40

4.5 GRAVIDADE DA LRA E CURVA DE SOBREVIDA........................ 42

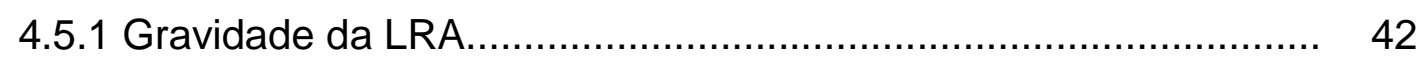

4.5.2 Curva de sobrevida.................................................................... 44

5 DISCUSSÃO

6 CONCLUSÕES.............................................................................. 55

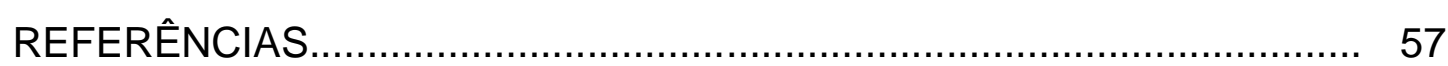

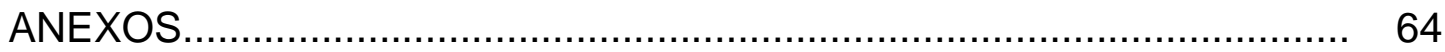


¿ర) 1 INTRODUÇÃ 


\section{INTRODUÇÃO}

A sepse representa a principal causa de morte em unidade de terapia intensiva $(\mathrm{UTI})^{(1,2)}$. Estudo multicêntrico realizado em UTIs brasileiras demonstrou que $16,7 \%$ do total de pacientes internados foram diagnosticados com sepse, sepse grave ou choque séptico e a taxa de mortalidade descrita foi $46,6 \%{ }^{(3)}$. Convencionalmente, a sepse é caracterizada por uma intensa resposta inflamatória associada à ativação do sistema imunológico frente a um estímulo infeccioso ${ }^{(4)}$.

A sepse pode causar disfunção de múltiplos órgãos (DMOs), síndrome em que se insere a lesão renal aguda $(\text { LRA })^{(4)}$. A LRA associada à sepse demonstra prevalência de aproximadamente $43 \%$, com taxas de mortalidade superiores a $70 \%$ para os pacientes submetidos à terapia de substituição renal ${ }^{(1,2,5,6)}$. Sendo assim, as disfunções renais, principalmente a LRA, é uma das complicações mais temíveis em pacientes com sepse, pois piora o prognóstico e aumenta substancialmente os custos do tratamento nas instituições de saúde ${ }^{(7)}$.

Na clínica, a LRA é caracterizada como redução abrupta da função renal com elevação do valor absoluto da creatinina sérica, igual ou superior a $0,3 \mathrm{mg} / \mathrm{dl}$ ou elevação de 1,5 vezes ou mais, quando comparada com a creatinina basal, ou volume urinário menor que $0,5 \mathrm{ml} / \mathrm{kg} / \mathrm{h}$ por seis horas ou mais $^{(8)}$.

A fisiopatologia da LRA induzida pela sepse é de causa multifatorial e envolve complexos mecanismos como a vasodilatação associada à hipoperfusão glomerular, a alteração na permeabilidade microvascular da rede de capilares peritubulares, a liberação de citocinas com intensa resposta inflamatória e disfunção tubular induzida pela lesão oxidativa ${ }^{(9)}$.

$\mathrm{Na}$ sepse, a primeira linha de defesa do hospedeiro, a imunidade inata, é desenvolvida por células fagocitárias (macrófagos, monócitos, granulócitos, polimorfonucleares), a seguir, as endotoxinas das bactérias gram negativas e principalmente o lipídeo $\mathrm{A}$ e o ácido teicóico das bactérias gram positivas ativam as imunoglobulinas que induzem uma resposta imune 
adquirida ou específica, com a liberação de mediadores inflamatórios primários como o fator de necrose tumoral- alfa (TNF- $\alpha$ ) e a interleucina-1 $(\mathrm{IL}-1)$. Essa reação celular desencadeia uma resposta inflamatória excessiva, com liberação de mediadores secundários que incluem as citocinas, os fatores de complemento, os prostanóides, a ativação do fator de agregação plaquetária (PAF) e a geração de espécies reativas de oxigênio (EROs) ${ }^{(10,11)}$.

A liberação de citocinas induz a expressão da enzima oxido nítrico sintase induzível (iNOS) na região da medula renal, nas células mesangiais glomerulares e nas células endoteliais da vasculatura renal, que aumenta a geração de óxido nítrico $(\mathrm{NO})^{(4,11)}$. A princípio, a expressão de NO é benéfica e resulta em ações de relaxamento vascular e inibe a agregação plaquetária e leucocitária com aumento do fluxo sanguíneo na microcirculação renal. No entanto, o aumento excessivo na geração de NO contribui para a evolução de mecanismos patológicos, como vasodilatação periférica, disfunção miocárdica, hipotensão e baixa resposta imunológica ${ }^{(4,5,12)}$.

Em casos de sepse grave e choque séptico, a tentativa de equilíbrio vasomotor resulta na indução de mediadores vasoconstritores como a endotelina-1, os leucotrienos e o tromboxano ${ }^{(10,11,13)}$. Esses mediadores são capazes de reduzir o fluxo sanguíneo renal (FSR) e promover a isquemia e hipóxia tecidual que incorrem em declínio da taxa de filtração glomerular $(\mathrm{TFG})^{(5,12)}$.

Além do mecanismo de hipóxia, as células manifestam alterações funcionais que resultam em trombose da microvasculatura e estados hiperglicêmicos $^{(10,11)}$. A ativação do PAF e da cascata de coagulação induz depósito de fibrina e trombose da microvasculatura renal, que pode evoluir para um quadro de coagulação intravascular disseminada (CIVD) ${ }^{(5)}$. Por outro lado, a hiperglicemia apresenta associação direta com a expressão de iNOS e a liberação de citocinas pró-inflamatórias como o TNF- $\alpha$ e a interleucina-6 (IL-6), que acentuam o processo inflamatório e a lesão oxidativa em células do túbulo renal ${ }^{(5,9,13)}$. 
Assim, o cenário inflamatório e trombótico com repercussão hemodinâmica já está descrito e sumariza o complexo e abrangente efeito devastador sistêmico da sepse, contudo, outras respostas celulares adjacentes, como a peroxidação lipídica, merecem destaque. Nesse contexto, observou-se o aumento da geração de EROs, que interferem diretamente na cascata de sinalização celular e exercem efeitos deletérios sobre as células dos túbulos renais, destacando-se a peroxidação lipídica da membrana celular, oxidação de proteínas e lesão no DNA ${ }^{(4,14)}$.

As EROs são representadas pelo ânion superóxido $\left(\mathrm{O}_{2}{ }^{-}\right)$, o peróxido de hidrogênio $\left(\mathrm{H}_{2} \mathrm{O}_{2}\right)$ e o radical hidroxila $\left(\mathrm{OH}^{-}\right)$. Em situações fisiológicas, a integridade celular é mantida pela ação de enzimas antioxidantes endógenas e destaca-se o superóxido dismutase (SOD), que neutraliza a ação do radical $\mathrm{OH}^{-}$, e as enzimas catalase e glutationa peroxidase que eliminam 0 $\mathrm{O}_{2}{ }^{--}$e $\circ \mathrm{H}_{2} \mathrm{O}_{2}{ }^{(14)}$. Entretanto, o desequilíbrio redox, em que prevalece a ação das partículas oxidantes, é potencialmente prejudicial para a função celular e está envolvido com o processo patológico da sepse ${ }^{(4,14)}$.

Na sepse, a ativação da resposta imune em combate a invasão de um micro-organismo resulta em grandes quantidade de $\mathrm{O}_{2}^{--}, \mathrm{OH}^{-}$e do intermediário $\mathrm{H}_{2} \mathrm{O}_{2}$, que afetam a funcionalidade de vários órgãos ${ }^{(14,15)}$. No meio intracelular, o ânion $\mathrm{O}_{2}{ }^{--}$, na presença de $\mathrm{NO}$, interage em uma reação secundária e forma peroxinitrito, um radical altamente oxidante ${ }^{(4,14)}$. A redução da reserva antioxidante pela excessiva formação de radicais livres leva à oxidação celular e contribui para o $\mathrm{DMOs}^{(13,14)}$.

Nos rins, o excesso de EROs também colabora com o desbalanço na hemodinâmica renal, possibilitando maior ativação de mediadores vasoconstritores. A prevalência vasoconstritora resulta na diminuição do FSR e consequente, redução da $\mathrm{TFG}^{(14)}$. Em condições fisiológicas, a integridade do citoesqueleto do epitélio tubular permite polarização da membrana, ou seja, a manutenção da assimetria da membrana basolateral com o transportador $\mathrm{Na-K}-\mathrm{ATPase}$ e a membrana apical com as estruturas que facilitam a entrada de sódio. Na sepse, as células perdem a sua polarização. A despolarização determina a disfunção no transporte de sódio 
e água ou morte celular e contribui para a descamação do epitélio tubular com deposição de restos celulares e outros fragmentos que causam obstrução intraluminal e vazamento transtubular do filtrado glomerular para o interstício renal $^{(12,16)}$.

Resumidamente, as alterações apresentadas nas células endoteliais e do epitélio renal culminam em redução da TFG e desequilíbrio na excreção de eletrólitos e água, com acúmulo de metabólitos nitrogenados como a

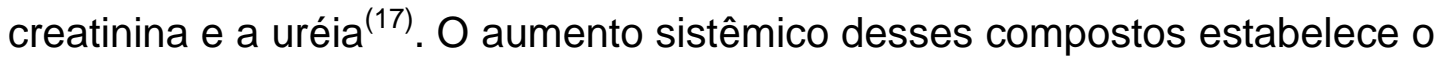
diagnóstico clínico da LRA, como mencionado no início dessa seção.

Os mecanismos oxidativos têm participação ativa em outros modelos de LRA. Estudo de Fonseca et al. (2012) demonstrou que o desiquilíbrio redox causou toxicidade tubular direta em animais tratados com poliximina$\mathrm{B}$, confirmando a nefrotoxicidade daquele fármaco ${ }^{(18)}$. Watanabe et al (2007) relataram que o aumento de peróxidos urinários e a diminuição das enzimas antioxidantes exerceram papel fundamental no desenvolvimento da LRA em modelo de isquemia(19). Outros modelos de nefropatia diabética e insuficiência renal crônica também apresentam excessiva geração de EROs e consumo de enzimas antioxidantes que resultam em lesão endotelial com disfunção da hemodinâmica glomerular e lesão oxidativa das células tubulares ${ }^{(20,21)}$.

Considerando as particularidades da LRA induzida por sepse, é de extrema importância analisar todas suas variáveis e buscar possibilidades para interferir nas complicações. Nesse contexto, destacam-se as intervenções farmacológicas que reduzem o mecanismo de lesão oxidativa na sepse. Dentre as alternativas de intervenção, as estatinas tem sido investigadas por suas ações pleiotrópicas, ou seja, não hipolipemiantes. As estatinas são anti-inflamatórias ${ }^{(22,23)}$, antioxidantes ${ }^{(24,25)}$, imunomoduladoras $^{(26)}$, antiploriferativas ${ }^{(23)}$, antitrombóticas e com ação de proteção endotelial $^{(25)}$.

Os efeitos mais relevantes das estatinas estão relacionados às ações anti-inflamatória e antioxidante. Estudo in vitro demonstrou que as estatinas 
são capazes de diminuir a ativação do fator de transcrição nuclear- $\beta$ (TNF- $\beta$ ) que reduz a liberação de citocinas inflamatórias, principalmente a produção de interleucinas, o TNF- $\alpha$, os quimioativos para monócitos-1 (MPC-1) e a proteína-C reativa $(\mathrm{PCR})^{(23)}$. O pré-condicionamento com estatinas diminuiu significativamente a disfunção endotelial induzida por endotoxemia em modelo experimental de lesão hepática em ratos, preveniu a infiltração de leucócitos e reduziu a geração de moléculas de adesão intercelular (ICAM-1) e EROs ${ }^{(25)}$. Outros estudos experimentais demonstram que a administração de estatina pode interferir na liberação de mediadores de diversas cascatas de imunomodulação, coagulação e oxidação ${ }^{(23,27)}$.

Foi realizado um estudo multicêntrico, randomizado, duplo-cego, com o objetivo de avaliar os efeitos da atorvastatina nos desfeches clínicos em pacientes com sepse grave. Os achados desse estudo associaram o uso da atorvastatina à menor incidência de DMOs e redução nas taxas de permanência hospitalar e de mortalidade ${ }^{(28)}$.

Nesse sentido, os dados obtidos de modelos experimentais in vitro, in vivo e estudos clínicos sugerem que a estatina seja um agente potencialmente benéfico em quadros de LRA induzida por sepse. No entanto, apesar de demonstrar potencial terapêutico promissor em quadros de resposta inflamatória exacerbada com efeito hemodinâmico disfuncional, os mecanismos de ação das estatinas sobre a LRA na sepse ainda precisam de melhor definição para a divulgação de dados mais determinantes que possam ter impacto na clínica.

Nesse cenário, a hipótese desse estudo é que o efeito antiinflamatório e antioxidante da estatina possa se sobressair na LRA induzida pela sepse com melhora funcional e sistêmica.

A busca por uma alternativa de intervenção terapêutica que obtenha resultados concretos no desenvolvimento e agravamento da LRA abre oportunidades para novos estudos que visem disponibilizar dados com impacto na saúde em geral e na melhora dos protocolos assistências destinados a pacientes críticos. 
U2 2 OBJETIVOS 


\section{OBJETIVOS}

\subsection{GERAL}

* Avaliar o efeito do pré-condicionamento com a sinvastatina em animais com LRA induzida por sepse.

\subsection{ESPECÍFICOS}

* Caracterizar a sepse por meio de parâmetros fisiológicos e crescimento bacteriano abdominal.

* Avaliar a função renal dos animais submetidos ao modelo experimental de sepse.

* Avaliar o perfil oxidativo renal dos animais submetidos ao modelo experimental de sepse.

* Classificar a gravidade da LRA e avaliar a sobrevida dos animais submetidos ao modelo experimental de sepse.

* Avaliar o efeito do pré-condicionamento com estatina sobre a função e perfil oxidativo renal, a gravidade da LRA e a sobrevida dos animais submetidos ao modelo experimental de sepse. 
3 MATERIAIS

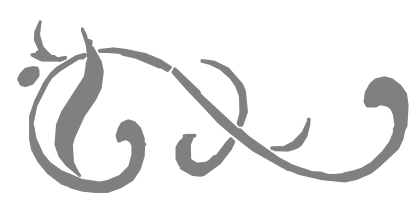

$\mathcal{E}$

MÉTODOS 


\section{MATERIAIS E MÉTODOS}

\subsection{MATERIAIS}

\subsubsection{Reagentes}

A água utilizada em todos os experimentos foi tratada por meio do sistema Nanopure da Bransead.

Todos os reagentes utilizados foram de grau analítico da marca Sigma, exceto quando especificado no texto.

\subsubsection{Animais}

Os procedimentos necessários para a realização deste estudo estão de acordo com os Princípios Éticos de Experimentação Animal adotado pelo Colégio Brasileiro de Experimentação Animal (COBEA) ${ }^{(29)}$. O estudo foi aprovado pelo Comitê de Ética em Uso de Animais da Faculdade de Medicina da Universidade de São Paulo (CEUA-FMUSP), protocolo registrado $\mathrm{n}^{0}$ 378/13. (Anexo A).

Foram utilizados ratos da raça Wistar, machos, pesando entre 250 e $350 \mathrm{~g}$. Os animais foram mantidos em gaiolas coletivas, com livre acesso a água e ração em condições térmicas com ciclos alternados de dia e noite.

Os animais foram pré-medicados com 1 a $5 \mathrm{mg} / \mathrm{kg}$ da solução de xilazina (Anasedan $\Theta$, Vetbrands), intraperitoneal (ip) com o objetivo de leve sedação e analgesia para os procedimentos anestésicos ou cirúrgicos. Após o procedimento cirúrgico, os animais permaneceram em observação para recuperação anestésica e do ato cirúrgico em mesa aquecida. Os animais submetidos à laparatomia receberam $2,5 \mathrm{mg} / \mathrm{kg}$ de morfina para analgesia, via subcutânea (sc), de quatro em quatro horas durante as 48 horas do período pós-cirúrgico ${ }^{(30)}$. Além disso, os animais receberam paracetamol na 
concentração de $2 \mathrm{mg} / \mathrm{ml}$ na água do bebedouro, durante todo o período pós-cirúrgico. Os bebedouros foram trocados a cada 12 horas $^{(31,32)}$.

Ao término do protocolo experimental, os animais foram eutanasiados por meio da coleta de sangue terminal pela punção da aorta abdominal sob efeito anestésico profundo induzido com a administração de 70-100 mg/kg da solução de tiopental sódico (Thiopentax®, Cristália) por via ip ${ }^{(33)}$. As carcaças de animais submetidos à eutanásia foram embaladas e acondicionadas em freezer e posterior encaminhamento para o descarte. $\mathrm{O}$ descarte foi realizado em saco branco, com o símbolo de "risco biológico", lacrados e depositados em containers para descarte de resíduos biológicos, localizados na área externa da Faculdade de Saúde Pública da Universidade de São Paulo (FSP-USP) para coleta em datas previamente estabelecidas pela instituição.

\subsection{PROCEDIMENTOS}

\subsubsection{Modelo de LRA induzida por sepse}

Os animais foram anestesiados com ketamina / xilazina $(75 \mathrm{mg} / \mathrm{kg}$ / $10 \mathrm{mg} / \mathrm{kg}$; Anasedan $\AA$, Vetbrands) por via ip ${ }^{(30,31)}$ e submetidos à laparotomia para realização do procedimento de ligadura e punção do cécum (LPC). Foi realizada uma incisão de aproximadamente dois centímetros na região do flanco esquerdo para visualização do cécum. $O$ cécum exposto foi ligado com fio prolene 5.0 à aproximadamente $15 \mathrm{~mm}$ do pólo cecal, além da estrutura da válvula ileocecal. $\mathrm{O}$ cécum ligado foi transfixado com agulha 40×12mm e foi realizada uma compressão delicada para saída de fezes pelo orifício da punção, extravasando para a cavidade abdominal. $O$ cécum foi recolocado na cavidade abdominal e a parede abdominal foi suturada com fio algodão $3.0^{(34)}$. 


\subsubsection{Ressuscitação volêmica}

Os animais submetidos ao procedimento cirúrgico de laparatomia receberam expansão volêmica com $25 \mathrm{ml} / \mathrm{kg}$ da solução de cloreto de sódio $0,9 \%$ que foi administrada por via ip, ao final do procedimento de LPC e na sexta, oitava e $24^{\circ}$ hora do período pós-cirúrgico ${ }^{(35,36)}$.

\subsubsection{Administração de estatina}

Os animais dos grupos Estatina, foram pré-condicionados com 0,5 $\mathrm{mg} / \mathrm{kg}$ de sinvastatina (Sinvascor®, Baldacci), por gavagem (vo), durante cinco dias, uma vez ao dia ${ }^{(37,38)}$.

\subsubsection{Apresentação dos grupos experimentais}

Os animais foram distribuídos nos seguintes grupos:

- SHAM (controle da sepse): os animais foram submetidos à laparotomia para a manipulação do cécum, porém sem a realização do procedimento de ligadura ou punção do segmento. Os animais receberam ressuscitação volêmica de acordo com o protocolo descrito;

- SHAM + Estatina: os animais foram pré-condicionados com 0,5 $\mathrm{mg} / \mathrm{kg}$ de sinvastatina por vo, conforme descrito. No quinto dia, eles foram submetidos à laparotomia, com simulação da LPC e início do protocolo de ressuscitação volêmica;

- Sepse: os animais foram submetidos à técnica de LPC e ao protocolo de ressuscitação volêmica;

- Sepse + Estatina: os animais foram tratados conforme descrito. No quinto dia, os animais foram submetidos à técnica de LPC e início do protocolo de ressuscitação volêmica. 


\subsubsection{Protocolo experimental}

\subsubsection{Gaiola metabólica}

Após 24 horas do ato cirúrgico, os animais foram colocados em gaiolas metabólicas para controle da ingesta hídrica e coleta de urina de 24 horas para avaliação da função renal e de metabólitos oxidativos (Figura 1).

Figura 1- Ilustrações da gaiola metabólica.
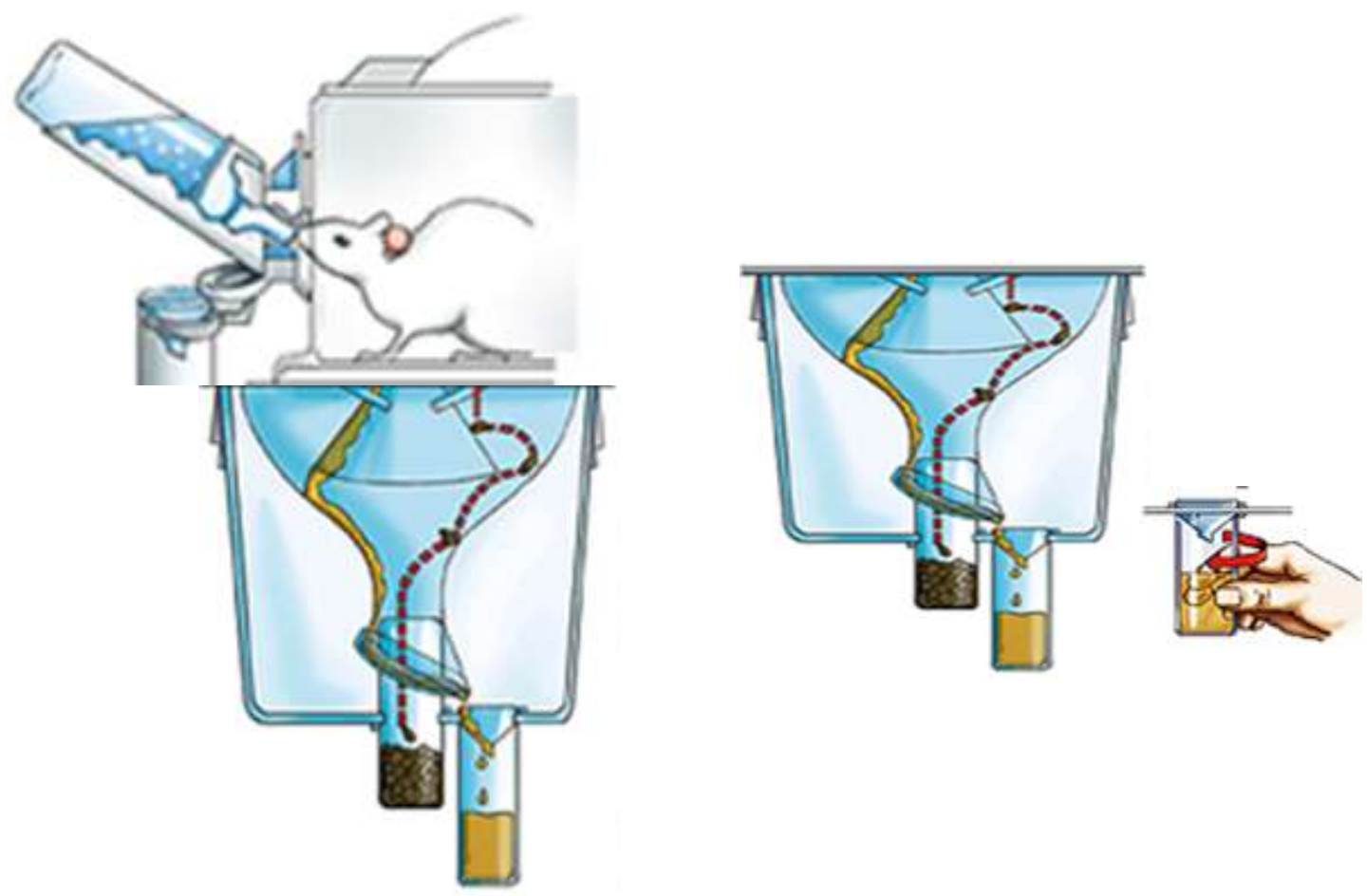

Fonte: Ilustração da gaiola metabólica. São Paulo: Tecnoplast: 2009.

\subsubsection{Avaliação dos parâmetros fisiológicos: temperatura retal e} glicemia capilar

Ao término do período de 24 horas na gaiola metabólica, os animais foram pré-medicados com um a cinco $\mathrm{mg} / \mathrm{kg}$ da solução de xilazina, via ip, com o objetivo de leve sedação e analgesia para posteriormente serem 
submetidos à anestesia profunda para coleta do líquido peritoneal e sangue total. Primeiramente, os animais foram posicionados para avaliação da temperatura retal com o termômetro clínico Premium Oval® de coluna de mercúrio. Os valores foram expressos em ${ }^{\circ} \mathrm{C}$. Em seguida, uma pequena amostra sanguínea foi obtida pela cauda do animal para avaliação da glicemia capilar com o monitor Accu-Chek Active ${ }^{\circledR}$. Os valores foram expressos em mg/dl.

\subsubsection{Cultura do líquido peritoneal}

Cerca de dois $\mathrm{ml}$ do líquido peritoneal foram coletados em cabine de fluxo laminar com técnica asséptica. A amostra foi transferida para um tubo de ensaio contendo $10 \mathrm{ml}$ do meio de cultura enriquecido TSB (Tryptic Soy Broth, Bacto ${ }^{\text {TM }}$ BD, Lot. 2206180). Todas as amostras ficaram em incubação em estufa por 14 dias à temperatura aproximada de $37^{\circ} \mathrm{C}$. Foram realizadas leituras nos períodos de 72 horas, sete dias e 14 dias para verificação da turvação do extrato. As amostras com turvação do extrato foram consideradas positivas para crescimento de micro-organismos ${ }^{(39)}$.

\subsubsection{Coleta de sangue total}

A coleta de sangue terminal foi realizada por meio da punção da aorta abdominal e posterior avaliação da função renal. Ao término da coleta, os animais foram eutanasiados segundo as normas éticas para manuseio de animais em laboratório, já descritas anteriormente.

\subsubsection{Sequência cronológica do protocolo experimental}

A Figura 2 representa a sequência cronológica do protocolo experimental. 
Figura 2- Sequência cronológica do protocolo experimental

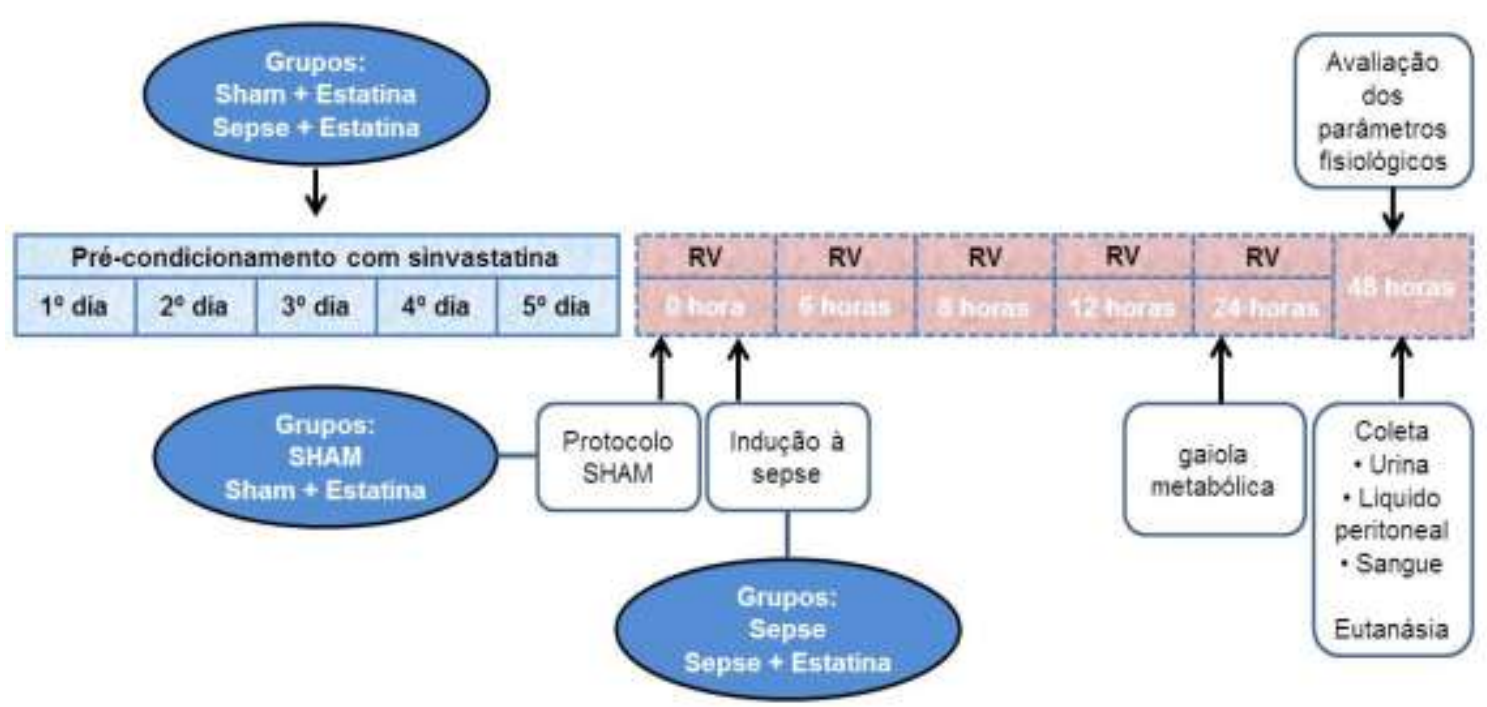

Sendo RV- ressuscitação volêmica.

Santos FN. Sequência cronológica do protocolo experimental [dissertação]. São Paulo: EEUSP: 2013.

\subsection{MÉTODOS}

\subsubsection{Função renal}

\subsubsection{Clearance de creatinina}

A função renal foi avaliada por meio do clearance de creatinina. $O$ método colorimétrico de Jaffé foi usado para determinar os valores da creatinina sérica e urinária. O clearance de creatinina foi obtido pela aplicação da fórmula (1) ${ }^{(20)}$ :

Clearance de creatinina $=$ creatinina urinária $\times$ fluxo urinário de $24 \mathrm{~h}$ creatinina sérica

Os valores do clearance de creatinina foram expressos em $\mathrm{ml} / \mathrm{min} / 100$ gramas. 


\subsubsection{Metabólitos Oxidativos}

\subsubsection{Peróxidos urinários}

Os peróxidos são encontrados em todos os fluídos corporais, especialmente na urina, as alterações de seus níveis são consideradas como potenciais indicadores da formação de EROs ${ }^{(40,41)}$.

A mensuração direta de peróxidos pode ser realizada através do método FOX-2, o qual consiste na utilização de ferro-xilenol laranja que oxidam 0 íon $\mathrm{Fe}^{2+}$ para íon $\mathrm{Fe}^{3+(40)}$. O xilenol laranja [ácido (0cresolsulfonaftalina 3' , 3" - bis (metilamino) ácido diacético] apresenta alta seletividade para o íon $\mathrm{Fe}^{3+}$ produzindo um complexo de coloração azularroxeado $\left(\alpha=4,3 \times 10^{4} \mathrm{M}^{-1} \mathrm{~cm}^{-1}\right)^{(41)}$.

O método FOX-2 foi utilizado neste estudo e a preparação da solução respeitou a seguinte ordem:

- $90 \mathrm{ml}$ de metanol;

- $10 \mathrm{ml}$ de água destilada;

- $100 \mu \mathrm{M}$ xilenol laranja;

- 4 mM BHT (2[6] - di-tert-butil-p-cresol);

- $25 \mathrm{mM}$ da solução se ácido sulfúrico $\left(\mathrm{H}_{2} \mathrm{SO}_{4}\right)$;

- $250 \mu \mathrm{M}$ de sulfato ferroso de amônio.

Na etapa seguinte, $900 \mu \mathrm{l}$ desta solução e $100 \mu \mathrm{l}$ da amostra da urina foram homogeneizadas e a solução permaneceu em repouso em temperatura ambiente por 30 minutos. A solução foi centrifugada para retirada de resíduos. Em seguida a leitura foi realizada por espectrofotometria em absorbância de $560 \mathrm{~nm}^{(40)}$.

Os valores foram estabilizados por grama de creatinina urinária expressos por nmol de peróxidos/grama creatinina urinária ${ }^{(40,41)}$. 


\subsubsection{Dosagem de TBARS urinário}

O malondeldeídeo (MDA) é um dos principais produtos da cascata de peroxidação lipídica que reage na presença do ácido tiobarbitúrico em fluídos orgânicos ${ }^{(42)}$.

A dosagem consiste na diluição de $0,2 \mathrm{ml}$ de urina em $0,8 \mathrm{ml}$ de água. A essa solução foram adicionados um $\mathrm{ml}$ de TCA a 17,5\% e um $\mathrm{ml}$ de ácido tiobarbitúrico a 0,6\%, pH 2. As amostras foram homogeneizadas e colocadas em banho maria (água fervente) durante 20 minutos $^{(36)}$. Ao término do tempo, a solução foi resfriada em gelo e adição de um $\mathrm{ml}$ de TCA a 70\%. As amostras foram homogeneizadas, tampadas e incubadas por 20 minutos. Ao fim desta etapa, as soluções foram centrifugadas por 15 minutos a 3000 rpm e a leitura foi realizada em espectrofotometria em absorbância de $534 \mathrm{~nm}^{(42)}$.

Os valores foram expressos por nmol de TBARS/grama creatinina urinária $^{(42)}$.

\subsubsection{Gravidade da LRA e curva de sobrevida}

A gravidade da LRA foi classificada de acordo com as alterações da creatinina sérica apresentadas pelos diversos grupos. Segundo o critério AKIN (Acute Kidney Injury Network), a LRA pode ser classificada em três estágios: o estágio AKIN-1 apresenta aumento de $0,3 \mathrm{mg} / \mathrm{dl}$ ou de uma a duas vezes o valor da creatinina sérica basal ou fluxo urinário menor que $0,5 \mathrm{ml} / \mathrm{kg} / \mathrm{h}$ por 6 horas; o estágio AKIN-2 mantém o aumento de 2 a 3 vezes em relação a creatinina sérica basal, ou fluxo urinário menor que $0,5 \mathrm{ml} / \mathrm{kg} / \mathrm{h}$ por 12 horas; o estágio AKIN-3 representa um aumento superior a 3 vezes o valor da creatinina sérica basal, ou fluxo urinário menor que $0,3 \mathrm{ml} / \mathrm{kg} / \mathrm{h}$ por 24 horas $^{(8)}$. Nesse estudo, o valor da creatinina basal se caracterizou pelos valores demonstrados pelo grupo SHAM.

Foi realizada a análise da taxa de sobrevivência dos animais dos diversos grupos por meio de uma adaptação da curva de sobrevida de Kaplan-Meier ${ }^{(43)}$. 


\subsection{ESTATÍSTICA}

Os resultados foram expressos em valores de média \pm desvio padrão. A variância entre os grupos foi analisada por meio do teste One Way ANOVA, seguida de pós-teste de comparações múltiplas de Newman-Keuls do programa estatístico Graph-Pad Prism version-3 for Windows $\AA$. A sobrevida dos animais foi determinada pela curva Kaplan-Meier. Foram considerados significantes valores de $p<0,05$.

\subsection{LOCAL}

O estudo foi desenvolvido no Laboratório Experimental de Modelos Animais (LEMA) da Escola de Enfermagem da Universidade de São Paulo (EEUSP), coordenado pela Profa ${ }^{-}$Dra $^{-}$Maria de Fatima Fernandes Vattimo. 
U2) 4 RESULTADOS 


\section{RESULTADOS}

\subsection{PARÂMETROS FISIOLÓGICOS}

\subsubsection{Peso corporal}

Tabela 1- Resultados referentes ao peso corporal dos grupos: SHAM, SHAM + Estatina, Sepse e Sepse + Estatina. São Paulo. 2013.

\begin{tabular}{lcc}
\hline \multicolumn{1}{c}{ Grupos } & n & $\begin{array}{c}\text { Peso } \\
\text { (gramas) }\end{array}$ \\
\hline SHAM & 8 & $298,8 \pm 31,7$ \\
SHAM + Estatina & 8 & $281,3 \pm 17,3$ \\
Sepse & 8 & $301,3 \pm 27,4$ \\
Sepse + Estatina & 8 & $278,8 \pm 8,4$ \\
\hline
\end{tabular}

Os dados apresentam médias \pm desvio padrão.

A Tabela 1 demonstra que os animais não apresentaram diferença significativa em relação ao seu peso corporal. 


\subsubsection{Temperatura corporal e glicemia capilar}

Tabela 2- Resultados referentes à temperatura corporal e glicemia capilar dos grupos: SHAM, SHAM + Estatina, Sepse e Sepse + Estatina. São Paulo. 2013.

\begin{tabular}{lccc}
\hline Grupos & N & $\begin{array}{c}\text { Temperatura } \\
(\mathbf{o} \mathbf{C})\end{array}$ & $\begin{array}{c}\text { Glicemia } \\
(\mathbf{m g} / \mathbf{d l})\end{array}$ \\
\hline SHAM & 8 & $36,7 \pm 0,6$ & $106,9 \pm 8,4$ \\
SHAM + Estatina & 8 & $36,4 \pm 0,3$ & $107,9 \pm 8,3$ \\
Sepse & 8 & $34,8 \pm 0,6^{\mathrm{ab}}$ & $299,0 \pm 7,2^{\mathrm{ab}}$ \\
Sepse + Estatina & 8 & $35,1 \pm 0,4^{\mathrm{ab}}$ & $300,4 \pm 9,3^{\mathrm{ab}}$ \\
\hline
\end{tabular}

${ }^{a} p<0,001$ vs SHAM

$\mathrm{b}_{\mathrm{p}}<0,001$ vs SHAM + Estatina

Os dados apresentam médias \pm desvio padrão.

$\mathrm{Na}$ Tabela 2 observa-se que os grupos SHAM e SHAM+Estatina apresentaram valores similares de temperatura corporal (SHAM: 36,7 $\pm 0,6^{\circ} \mathrm{C}$, SHAM+Estatina: $\left.36,4 \pm 0,3^{\circ} \mathrm{C}\right)$. Os grupos Sepse e Sepse+Estatina demonstraram redução significativa desse parâmetro quando comparados ao grupo SHAM (Sepse: $34,8 \pm 0,6^{\circ} \mathrm{C}$, Sepse+Estatina: $35,1 \pm 0,4^{\circ} \mathrm{C}$ vs SHAM: $\left.36,7 \pm 0,6^{\circ} \mathrm{C}, \mathrm{p}<0,001\right)$.

Em relação à glicemia capilar, os grupos controles apresentaram valores que foram considerados parâmetros de normalidade para esse

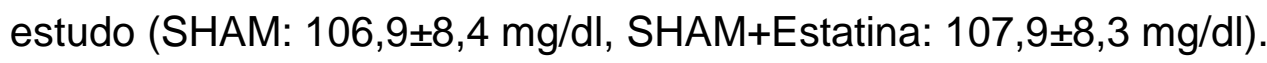

Os animais com indução da sepse demonstraram elevação significativa da glicemia capilar em relação ao grupo SHAM e SHAm+Estatina (Sepse: 299,0 $\pm 7,2 \mathrm{mg} / \mathrm{dl}$, Sepse+Estatina: 300,4 $\pm 9,3 \mathrm{mg} / \mathrm{dl}$ vs SHAM: $106,9 \pm 8,4 \mathrm{mg} / \mathrm{dl}$ e SHAM+Estatina: 107,9 $\pm p<0,001)$. 


\subsection{CULTURA DO LÍQUIDO PERITONEAL}

Quadro 1- Classificação das culturas do líquido peritoneal dos grupos SHAM e Sepse nos diferentes períodos.

\begin{tabular}{|l|c|c|c|c|}
\hline Grupos & $\mathbf{n}$ & $\mathbf{7 2}$ horas & $\mathbf{7}$ dias & 14 dias \\
\hline SHAM & 6 & negativa & negativa & negativa \\
\hline Sepse & 8 & positiva & positiva & positiva \\
\hline
\end{tabular}

Santos FN. Classificação das culturas do líquido peritoneal dos grupos SHAM e Sepse [dissertação]. São Paulo: EEUSP: 2013.

O Quadro 1 resume os resultados da cultura do líquido peritoneal dos grupos SHAM e Sepse. O grupo SHAM apresentou resultado negativo para o crescimento de microrganismo, com ausência de alterações no extrato em 72 horas, sete dias e 14 dias de incubação. Por outro lado, o grupo Sepse demonstrou resultado positivo para cultura do líquido peritoneal com turvação do extrato em 72 horas, sete dias e 14 dias de incubação (Figura 3).

Figura 3 - Cultura do líquido peritoneal dos animais dos grupos SHAM e Sepse nos diferentes períodos.

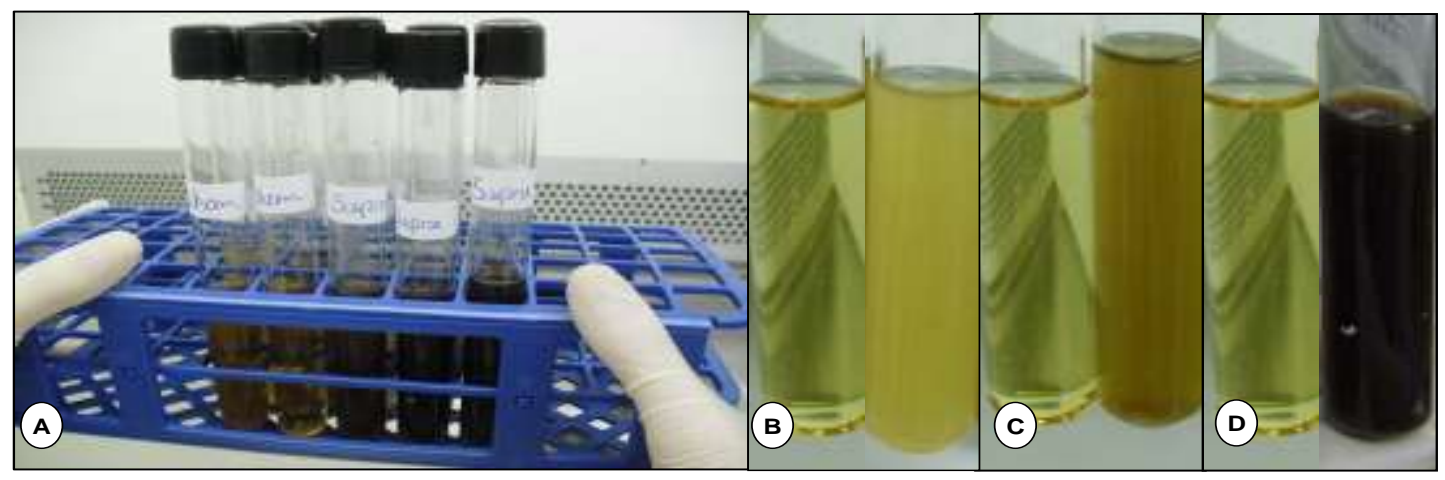

Fotos ilustrativas da cultura do líquido peritoneal (A), cultura do grupo Controle e Sepse, respectivamente, em 72 horas (B), 7 dias (C) e 14 dias (D).

Santos FN. Cultura do líquido peritoneal dos animais dos grupos SHAM e Sepse [dissertação]. São Paulo: EEUSP: 2013 


\subsection{FUNÇÃO RENAL}

\subsubsection{Clearance de creatinina}

Tabela 3- Resultados referentes à função renal global segundo os grupos: SHAM, SHAM + Estatina, Sepse e Sepse + Estatina. São Paulo. 2013.

\begin{tabular}{lccccc}
\hline Grupos & $\mathbf{n}$ & $\begin{array}{c}\text { Fluxo urinário } \\
(\mathbf{m l} / \mathbf{m i n})\end{array}$ & $\begin{array}{c}\text { Cr urinária } \\
(\mathbf{m g} / \mathbf{d l})\end{array}$ & $\begin{array}{c}\text { Cr sérica } \\
(\mathbf{m g} / \mathbf{d l})\end{array}$ & $\begin{array}{c}\text { Clcr/ 100g } \\
(\mathbf{m l} / \mathbf{m i n})\end{array}$ \\
\hline SHAM & 8 & $0,015 \pm 0,003$ & $57,66 \pm 17,5$ & $0,32 \pm 0,08$ & $0,85 \pm 0,08$ \\
SHAM + Estatina & 8 & $0,014 \pm 0,002$ & $58,06 \pm 12,5$ & $0,35 \pm 0,08$ & $0,83 \pm 0,09$ \\
Sepse & 8 & $0,007 \pm 0,003^{\mathrm{ab}}$ & $99,52 \pm 37,3$ & $0,93 \pm 0,11^{\mathrm{ab}}$ & $0,22 \pm 0,07^{\mathrm{ab}}$ \\
Sepse + Estatina & 8 & $0,009 \pm 0,002^{\mathrm{ab}}$ & $49,82 \pm 16,1$ & $0,41 \pm 0,10^{\mathrm{ac}}$ & $0,46 \pm 0,08^{\text {ade }}$ \\
\hline
\end{tabular}

Sendo: $\mathrm{Cr}$ - creatinina, $\mathrm{Clcr}$ - clearance de creatinina.

${ }^{a} p<0,001$ vs SHAM

$b_{p}<0,001$ vs SHAM + Estatina

${ }^{c} p<0,001$ vs Sepse

$\mathrm{d}<<0,01$ vs SHAM + Estatina

${ }^{e} p<0,05$ vs Sepse

Os dados apresentam médias \pm desvio padrão.

A Tabela 3 aponta os dados referentes à função renal global dos grupos experimentais. Os animais que sofreram indução da sepse apresentaram redução significativa do fluxo urinário, mesmo quando receberam o pré-tratamento com sinvastatina em relação aos grupos controle (Sepse: 0,007 $\pm 0,003 \mathrm{ml} / \mathrm{min}$, Sepse+Estatina: 0,009 $\pm 0,002 \mathrm{ml} / \mathrm{min}$ vs SHAM: $0,015 \pm 0,003 \mathrm{ml} / \mathrm{min}$ e SHAM+Estatina $0,014 \pm 0,002 \mathrm{ml} / \mathrm{min}$, $p<0,001)$.

Em relação ao parâmetro creatinina urinária, os grupos não demonstraram diferença estatisticamente significante entre si. 
Os animais sepse apresentaram elevação significativa da creatinina sérica quando comparados ao grupo SHAM e SHAM + Estatina (Sepse: 0,93 $\pm 0,11 \mathrm{mg} / \mathrm{dl}$ vs SHAM: 0,32 $\pm 0,08 \mathrm{mg} / \mathrm{dl}$, SHAM + Estatina: 0,35 $\pm 0,08$, $p<0,001)$. A administração de sinvastatina nos animais com sepse reduziu significativamente a creatinina sérica em relação ao grupo Sepse

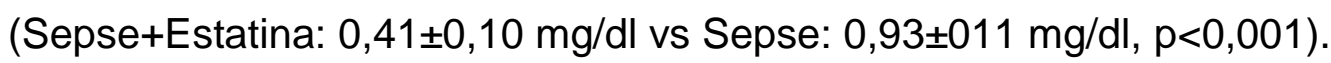

O grupo SHAM apresentou valores de função renal pelo clearence de creatinina que possibilitaram sua utilização como grupo controle para os demais, uma vez que, estiveram de acordo com os adotados em outros estudos $^{(19,20,44)}$. Sendo assim, os grupos que comparados, apresentaram redução estatisticamente significante no clearance de creatinina, foram considerados como portadores de LRA $(p<0,05)$.

Os animais sepse apresentaram declínio significativo do clearance de creatinina (Sepse: 0,22 $\pm 0,07 \mathrm{ml} / \mathrm{min}$ vs SHAM: 0,85 $\pm 0,08 \mathrm{ml} / \mathrm{min}, \mathrm{p}<0,001$ ). Em contrapartida, observou-se que o pré-condicionamento com sinvastatina em animais sepse determinou a elevação significativa dos valores do clearance de creatinina quando comparados ao grupo Sepse (Sepse + Estatina: 0,46 $\pm 0,08 \mathrm{ml} / \mathrm{min}$ vs Sepse: 0,22 $\pm 0,07 \mathrm{ml} / \mathrm{min}, \mathrm{p}<0,05)$, no entanto, esse grupo mantém valores de clearence inferiores aos grupos SHAM e

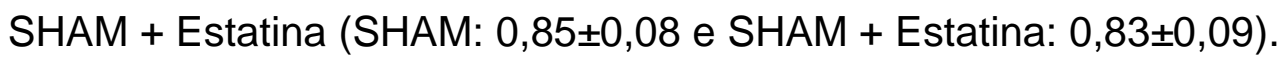




\subsection{METABÓLITOS OXIDATIVOS}

\subsubsection{Peróxidos e TBARS urinários}

Tabela 4- Resultados referentes aos valores de peróxidos e TBARS urinários dos grupos: SHAM, SHAM + Estatina, Sepse e Sepse + Estatina. São Paulo. 2013.

\begin{tabular}{lccc}
\hline Grupos & $\mathbf{n}$ & $\begin{array}{c}\text { Peróxidos urinários } \\
\text { (nmol/g de CrU) }\end{array}$ & $\begin{array}{c}\text { TBARS urinário } \\
\text { (nmol/g de CrU) }\end{array}$ \\
\hline SHAM & 8 & $5,1 \pm 1,2$ & $219,5 \pm 15,3$ \\
SHAM + Estatina & 8 & $6,3 \pm 2,8$ & $223,6 \pm 16,3$ \\
Sepse & 8 & $21,3 \pm 4,5^{\mathrm{ab}}$ & $954,6 \pm 26,6^{\mathrm{de}}$ \\
Sepse + Estatina & 8 & $11,6 \pm 4,1^{\mathrm{c}}$ & $626,7 \pm 23,6^{\text {def }}$ \\
\hline
\end{tabular}

Sendo: CrU - creatinina urinária, TBARS - substâncias reativas ao ácido tiobarbitúrico.

${ }_{\mathrm{a}}^{\mathrm{a}}<<0,01$ vs SHAM

${ }^{b} p<0,01$ vs SHAM + ESTATINA

${ }^{c} p<0,05$ vs Sepse

$p<0,001$ vs SHAM

$e_{p}<0,001$ vs SHAM + ESTATINA

$\mathrm{f} p<0,001$ vs Sepse

Observa-se que, em relação aos peróxidos, o grupo SHAM apresenta resultados considerados como normalidade para este parâmetro (SHAM: $5,1 \pm 1,2 \mathrm{nmol} / \mathrm{g}$ de $\mathrm{CrU}$ ), enquanto que o grupo Sepse, quando comparado ao grupo SHAM e SHAM+Estatina, apresentou elevação estatisticamente significante na excreção de peróxidos urinários (Sepse: $21,3 \pm 4,5 \mathrm{nmol} / \mathrm{g}$ de CrU vs SHAM: $5,1 \pm 1,2 \mathrm{nmol} / \mathrm{g}$ de CrU, SHAM+Estatina: $6,3 \pm 2,8 \mathrm{nmol} / \mathrm{g}$ de CrU, $p<0,01)$. Já o grupo Sepse+Estatina, quando comparado ao grupo Sepse demonstrou redução significativa dos peróxidos urinários (Sepse+Estatina: $11,6 \pm 4,1 \mathrm{nmol} / \mathrm{g}$ de CrU vs Sepse: $21,3 \pm 4,5 \mathrm{nmol} / \mathrm{g}$ de $\mathrm{CrU}, \mathrm{p}<0,05)$. 
Quanto aos TBARS, constatou-se que grupo Sepse apresentou maiores níveis desse metabólito quando comparado aos grupos SHAM e SHAM+Estatina (Sepse: 954,6 $\pm 26,6 \mathrm{nmol} / \mathrm{g}$ de CrU vs SHAM: 219,5 $\pm 15,3$ $\mathrm{nmol} / \mathrm{g}$ de CrU, SHAM + Estatina: 223,6,6 $\pm 16,3 \mathrm{nmol} / \mathrm{g}$ de $\mathrm{CrU}, \mathrm{p}<0,001)$.

O pré-condicionamento com sinvastatina reduziu significativamente os níveis de TBARS dos animais sepse (Sepse+Estatina: 626,7 $\pm 23,6 \mathrm{nmol} / \mathrm{g}$ de CrU vs Sepse: 954,6 $\pm 26,6 \mathrm{nmol} / \mathrm{g}$ de $\mathrm{CrU}, \mathrm{p}<0,001)$. 


\subsection{GRAVIDADE DA LRA E CURVA DE SOBREVIDA}

\subsubsection{Gravidade da LRA}

Gráfico 1- Estágios de gravidade da LRA dos grupos SHAM, SHAM + Estatina, Sepse e Sepse + Estatina.

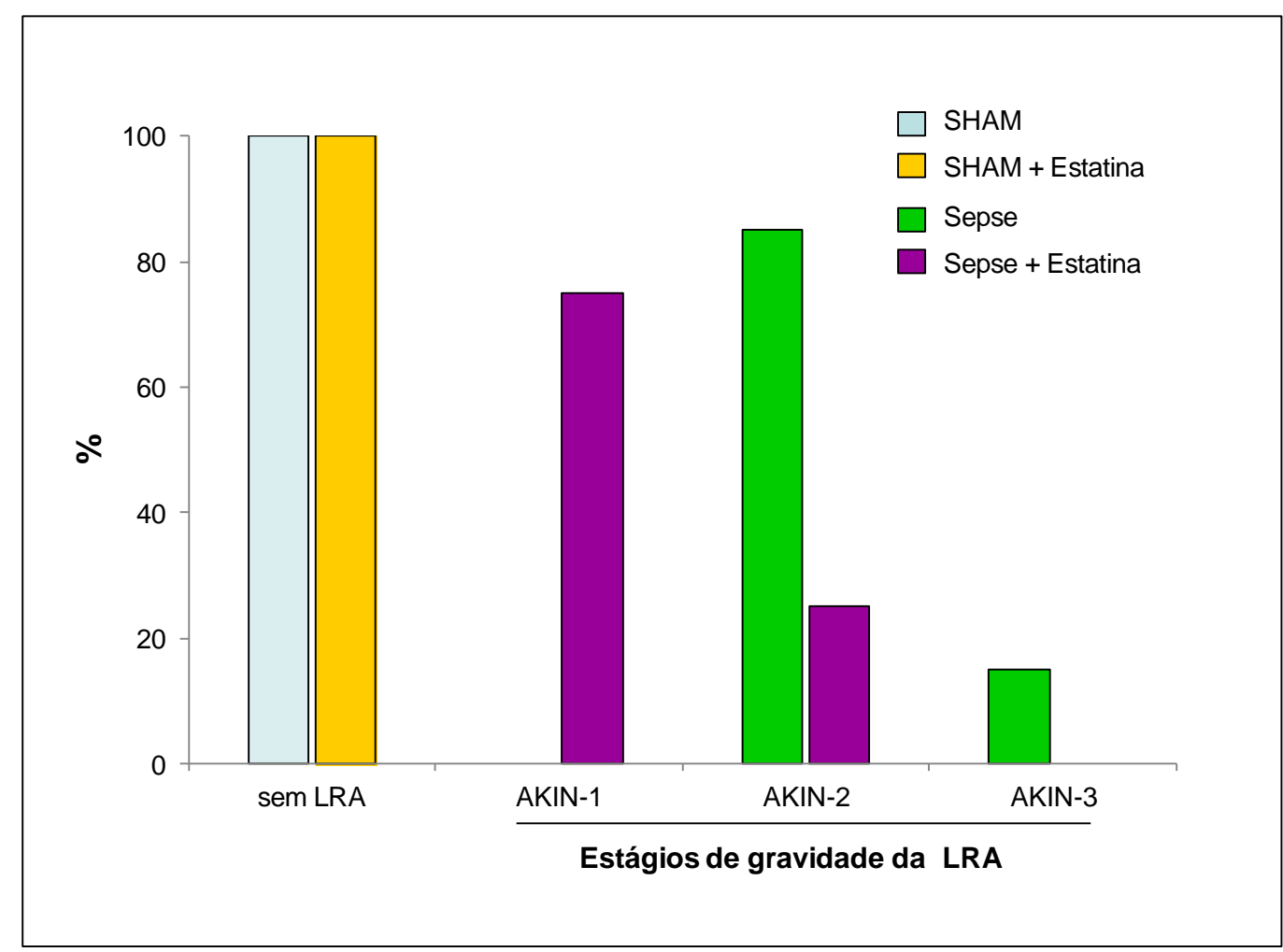

Os estágios de gravidade da LRA foram estratificados por meio da variação dos valores de creatinina sérica dos diversos grupos.

Santos FN. Estágios de gravidade da LRA dos grupos SHAM, SHAM + Estatina, Sepse e Sepse + Estatina [dissertação]. São Paulo: EEUSP: 2013.

O Gráfico 1 demonstra a classificação da gravidade de LRA entre os grupos SHAM e Sepse tratado ou não tratado. Observou-se no estudo que os grupos SHAM e SHAM + Estatina apresentaram valores de creatinina 
sérica que foram considerados referência de normalidade, sendo assim, esses animais foram classificados como "sem LRA".

Segundo o critério AKIN para classificação de gravidade da LRA, , $85 \%$ dos animais do grupo sepse foram classificados no estágio AKIN-2 e $15 \%$ como AKIN-3, enquanto que os animais pré-condicionados com sinvastatina foram estratificados em estágio AKIN-1 (75\%) e para o critério AKIN-2 (15\%). 


\subsubsection{Curva de sobrevida}

Gráfico 2 - Curva de sobrevida dos grupos SHAM, SHAM + Estatina, Sepse e Sepse + Estatina.

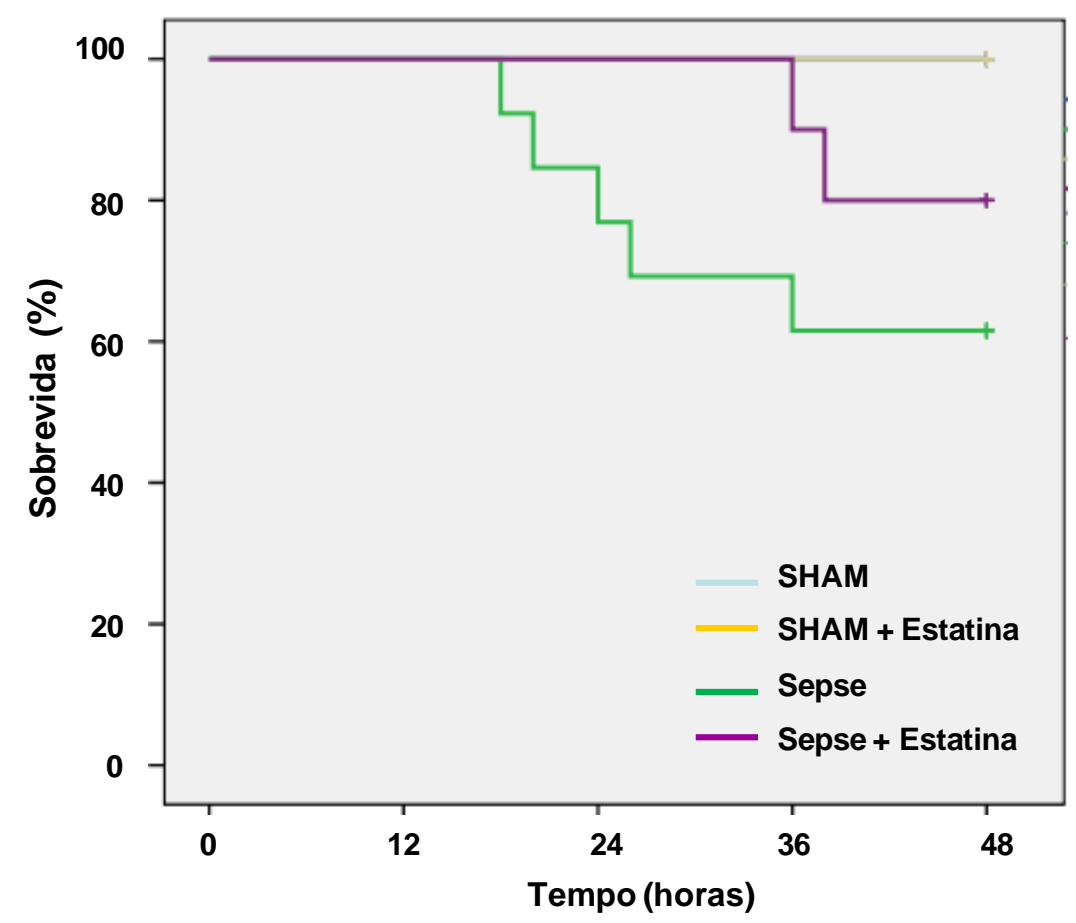

Curva de sobrevida Kaplan-Meier adaptada para os diversos grupos: SHAM ( $n=8)$, SHAM+Estatina $(n=8)$, Sepse $(n=13)$ e Sepse+Estatina $(n=10)$. Nota: $n=$ número total de animais por grupo experimental.

Santos FN. Curva de sobrevida dos grupos SHAM, SHAM + Estatina, Sepse e Sepse + Estatina [dissertação]. São Paulo: EEUSP: 2013.

A curva de sobrevida de Kaplan-Meier adaptada para os diversos grupos está representada no Gráfico 2. Os grupos controle representados pelo SHAM e SHAM + Estatina permaneceram com a taxa de sobrevida de $100 \%$. Os animais submetidos à técnica de LPC apresentaram taxa de sobrevida de $62 \%$ e o pré-condicionamento com sinvastatina determinou elevação da taxa de sobrevida dos animais sepse para $80 \%$. 
(ช) 5 DISCUSSÃO 


\section{DISCUSSÃO}

O presente estudo demonstrou que o pré-condicionamento com a sinvastatina em ratos com LRA induzida por sepse atenuou a disfunção renal, com elevação da TFG e diminuiu a liberação de metabólitos oxidativos, demonstrando repercussão favorável na gravidade da LRA e na sobrevida dos animais.

Sabe-se que a LRA é uma complicação frequente em casos de sepse grave e choque séptico. Para melhor compreender o desenvolvimento da LRA induzida por sepse, nesse estudo foi utilizada a técnica de LPC. A perfuração da parede intestinal promove o extravazamento gradativo do conteúdo cecal para a cavidade abdominal que induz a peritonite e evolução para sepse e choque séptico ${ }^{(8)}$. A migração de micro-organismos patogênicos do trato gastrointestinal para a circulação sistêmica é uma das principais causas de sepse e se assemelha ao quadro de sepse de origem abdominal apresentado em humanos decorrente de traumas com perfurações das alças intestinais, colite ou peritonite pós-operatória ${ }^{(8,45)}$.

Os resultados desse estudo reiteraram a precisão do modelo de LPC, uma vez que os animais evoluíram com parâmetros fisiológicos característicos do quadro de sepse. Eles apresentaram redução da temperatura corporal, aumento da taxa de glicemia capilar e presença de micro-organismos na cultura do líquido peritoneal. Segundo a definição da “International Sepsis Definitions Conference" realizada no ano de 2001, o diagnóstico da sepse é sugerido por achados clínicos inespecíficos primários, como a hipotermia ou febre, taquicardia, hipotensão e taquipnéia. $\mathrm{Na}$ clínica, os achados laboratoriais revelam leucocitose ou leucopenia, hiperglicemia e hiperlactatemia. Posteriormente, a síndrome é confirmada pelo isolamento do agente etiológico em culturas de diferentes materiais biológicos ${ }^{(46)}$. 
Apesar dos esforços da comunidade científica, até o momento não existe um tratamento específico para o controle da sepse grave ou choque séptico em pacientes. Logo, o tratamento consiste em medidas de suporte como a administração de drogas vasoativas, ventilação mecânica e terapias de substituição, que preservam a funcionalidade do órgão enquanto se aguarda a ação dos antibióticos ${ }^{(47)}$.

As diretrizes atuais do "Surviving Sepsis Campain" recomendam como intervenção imediata diante do diagnóstico, a ressuscitação volêmica intravenosa, a administração de drogas vasoativas, a oferta de oxigênio, e quando necessário, a ventilação mecânica ${ }^{(48)}$. Essas medidas interferem de forma positiva na taxa de mortalidade em pacientes com sepse ${ }^{(49)}$.

Em nosso estudo, todos os animais receberam reposição volêmica com solução de cloreto de sódio 0,9\%. A hiperhidratação foi essencial para manutenção dos animais submetidos à técnica de LPC, uma vez que o modelo reproduz uma condição clínica grave, o que justifica a alta mortalidade dos animais ${ }^{(8)}$. Estudo experimental em modelos in vivo descreve que a falência da microcirculação atua como fator crucial na sepse em modelo de infusão de lipolissacarídeos ou técnica de LPC. Nele, a ressuscitação volêmica se torna essencial para atenuar os distúrbios da microcirculação e alterações hemodinâmicas ${ }^{(35)}$.

As primeira ações em relação ao foco infeccioso são o diagnóstico e a coleta de culturas, para posterior início da terapia antibiótica empírica ${ }^{(49)}$. A administração empírica de antibiótico deve considerar a particularidade de cada paciente como o local em que a infecção se desenvolveu, a associação com doença crônica e especialmente susceptibilidade do microorganismo $^{(50)}$.

Após as primeiras seis horas, o objetivo de ação se volta para monitorização, controle e medidas de suporte para a $\mathrm{DMOs}^{(48)}$. A primeira manifestação em resposta a sepse severa é a redução da oxigenação para os tecidos devido a hipotensão e a trombose microvascular ${ }^{(49)}$. Paralelamente, ocorre a hiperglicemia com alta prevalência em pacientes com diagnóstico de sepse grave ${ }^{(51)}$. A hiperglicemia de estresse, ou o 
quadro de hiperglicemia apresentado pelos animais submetidos à LPC, é resultante da produção excessiva de glicose pelas células hepáticas, aumento da resistência à insulina, em pacientes de UTI, decorrentes de tratamento como a administração contínua de corticoides e infusões em solução de glicose. Evidências afirmam que a hiperglicemia é uma resposta fisiológica e benéfica das células e frequentemente bem tolerada pelo organismo. Dessa forma, a hiperglicemia só deve ser tratada quando a excreção renal de glicose resulte em diurese osmótica e consequente hipovolemia do paciente ${ }^{(47)}$. Assim sendo, para o controle da hiperglicemia em pacientes de UTI com sepse grave inicia-se a terapia com insulina quando os níveis de glicose sérica sejam superiores a $180 \mathrm{mg} / \mathrm{dl}$, com o objetivo de manter a glicose sérica entre $144-180 \mathrm{mg} / \mathrm{dl}^{(52)}$.

Os quadros de sepse e choque séptico envolvem hipóxia, disfunção e trombose da microcirculação, resposta inflamatória e a evolução para a síndrome da DMOs. Nos rins, a disfunção da microvasculatura aumenta a permeabilidade capilar e reduz o FSR, com aumento desproporcional da ação vasodilatadora na arteríola aferente em relação a eferente. A redução da pressão em arteríola aferente, reduz o gradiente de pressão intraglomerular, diminuindo a $\mathrm{TFG}^{(53)}$, com consequente oligúria e ávida absorção de sódio pelo mecanismo feedback tubuloglomerular ${ }^{(8)}$. Nesse estudo, o declínio da TFG, com a redução do clearance de creatinina e a diminuição do fluxo urinário, caracterizou a LRA oligúrica em animais do grupo Sepse.

A hipoperfusão favorece a hipóxia e a isquemia tecidual que aceleram o processo de morte celular, principalmente por apoptose em células renais, cardíacas e pulmonares. Esse quadro caracteriza a síndrome $\mathrm{DMOs}^{(4)}$. A hipóxia celular e a interação entre o micro-organismo e o sistema imune do hospedeiro contribuem para formação de $\operatorname{EROs}^{(4,14,17)}$.

Em condições de hipóxia tecidual, o ATP celular é rapidamente consumido e resulta no acúmulo de hipoxantina no interior da célula renal. $\mathrm{Na}$ reperfusão, todo o estoque de hipoxantina é transformado em xantina e ácido úrico. Essa reação gera $\mathrm{O}_{2}{ }^{--} \mathrm{e} \circ \mathrm{OH}^{-}$, radicais altamente citotóxicos, 
que em contato com o NO geram o peroxinitrito, mais tóxico do que qualquer de seus precursores ${ }^{(4,14)}$.

Nesse estudo, o aumento de metabólitos oxidativos na urina no grupo submetido à LPC confirmou a geração de EROs, com subsequente lesão oxidativa e disfunção renal. Estudo in vivo realizado em ratos relatou aumento de metabólitos oxidativos após três horas da indução de sepse por técnica de LPC e desequilíbrio no mecanismo redox com alteração na geração de enzimas antioxidantes. Ressalte-se que esta característica foi apresentada principalmente em animais não sobreviventes ${ }^{(54)}$. O efeito benéfico de antioxidantes foi demontrado em um estudo prospectivo, randomizado, duplo cego realizado em pacientes de UTI que receberam suplementação antioxidante na dieta enteral, tendo sido observado redução de metabólitos oxidativos e reestabelecimento do equilíbrio redox ${ }^{(55)}$.

A LRA é uma disfunção que envolve manifestações clínicas, que podem se apresentar com mínima alteração da creatinina sérica, com evolução para anúria e posterior falência renal. Estudos epidemiológicos demonstram associação entre incidência de LRA e aumento da taxa de mortalidade, particularmente para pacientes com necessidade de terapias de substituição renal (diálise) $)^{(1,56)}$.

Em uma abordagem atual, os critérios diagnósticos que envolvem a avaliação do fluxo urinário e da creatinina sérica são utilizados para identificação do estágio de comprometimento da função renal. Esses critérios monitoram a progressão da LRA e ainda podem alertar para intervenções preventivas ${ }^{(7,57)}$.

Em 2004, o grupo AKIN estabeleceu novas diretrizes para o diagnóstico e classificação, segundo a gravidade da LRA, em AKIN-1, AKIN2 e AKIN-3. Na clínica, a classificada AKIN-3 inclui todos os pacientes mais graves, em terapia de substituição renal $^{(7)}$.

No estudo ora apresentado, a gravidade da LRA foi classificada de acordo com o critério AKIN, utilizando-se o valor da creatinina sérica. Os resultados mostraram que o grupo Sepse apresentou maior gravidade da 
LRA, haja vista que $85 \%$ dos animais foram estratificados no estágio AKIN-2 e $15 \%$ no estágio AKIN-3. A taxa de mortalidade entre esses animais sepse foi de $38 \%$. Peng et al. (2012) observaram os mesmos resultados em estudo de modelo animal, no qual o aumento da mortalidade dos grupos estava relacionado a gravidade da LRA, à semelhança do que foi observado nesse estudo $^{(43)}$

O diagnóstico precoce da LRA em estágios iniciais permite o emprego de medidas terapêuticas que evitam a evolução da LRA para um estágio mais grave. Entre essas medidas, destaca-se na clínica a terapia de substituição renal, que quando aplicada precocemente pode reduzir os riscos para morbidades e diminuir a taxa de mortalidade ${ }^{(58)}$. Portanto, é possível constatar que a gravidade da LRA está diretamente relacionada à sobrevida. Um estudo multicêntrico confirma a associação positiva entre a gravidade da LRA e a mortalidade entre pacientes críticos ${ }^{(59)}$.

Um fator que interfere de forma positiva na terapêutica da sepse é a prevenção da DMOs, ou seja, as investigações focadas em reações secundárias para redução da geração de EROs ou inibição da cascata de anticoagulação demonstram resultados promissores para proteção de órgãos, particularmente, os rins e pulmões ${ }^{(4,10,11)}$.

Entre essas possibilidades, destacam-se as estatinas, que pertencem à classe de medicamentos com ação hipolipemiante, com a capacidade de reduzir a ação da enzima 3-hidroxi-3-metilglutaril coenzima A (HMG-CoA) redutase. A HMG-CoA redutase cataliza a conversão da hidroximetilglutarilCoA para mevalonato que inibe a biossíntese do colesterol. Na prática clínica, isso se reflete na redução dos níveis séricos de colesterol total, colesterol lipídico de baixa densidade (LDL), apolipoproteina B e triglicerídeos ${ }^{(60,61)}$.

Além dos efeitos hipolipemiantes, as estatinas possuem outras propriedades terapêuticas significativas. Ressaltam-se as ações antiinflamatória, antioxidante, antimicrobiana e imunomoduladora que podem servir como agentes adjuvantes no tratamento complementar na sepse ${ }^{(23)}$. 
Foi possível evidenciar nesse estudo que o pré-condicionamento com a sinvastatina exerceu efeito protetor sobre a função renal dos animais submetidos à técnica de LPC. Apesar de não ter sido observado melhora do fluxo urinário, a sinvastatina elevou o clearance de creatinina que confirmou a recuperação da função renal. Isso provavelmente ocorreu em resposta à sua ação antioxidante, que foi evidênciada pela redução de peróxidos e TBARS urinários.

A proteção antioxidante com o pré-condicionameto com a estatina foi demonstrada por vários estudos experimentais. A administração de sinvastatina em modelo de nefrotoxicidade induzida pela cisplatina resultou em melhora da função renal, com aumento no nível de enzimas antioxidantes e redução de metabólitos oxidativos como o MDA ${ }^{(62)}$. Ainda, em outro modelo de nefrotoxicidade induzida pelo contraste iodado, a administração sinvastatina confirmou aumento da taxa de enzimas antioxidantes e redução de mediadores oxidativos, como o $\mathrm{NO}^{(24)}$. Em estudo in vivo com o modelo de LRA isquêmica associado ao tratamento com estatinas, realizado nesse laboratório - LEMA, observou-se resultados semelhantes, com redução de espécies oxidantes como os $\mathrm{H}_{2} \mathrm{O}_{2}$ e o MDA e consequente melhora da função renal ${ }^{(37,38)}$.

Adicionalmente, constatou-se que a maioria dos animais do grupo Sepse+Estatina (75\%) foram classificados no estágio AKIN-1 para gravidade da LRA com melhora na taxa de sobrevida e redução da mortalidade para $20 \%$. Esses resultados confirmam uma relação direta entre os valores de creatinina sérica, estágio de gravidade da LRA e a taxa de mortalidade dos animais com sepse.

Dados clínicos também tem demonstrado o uso de estatina em pacientes com sepse, reforçando suas propriedades pleiotrópicas. Estudo retrospectivo analisou pacientes de UTI com diagnóstico de sepse grave, em que o grupo de pacientes com tramento prévio com estatina apresentou redução relativa de $35 \%$ na mortalidade em relação ao grupo sem uso prévio de estatina ${ }^{(63)}$. Em estudo prospectivo realizado com base no registro nacional de prescrições em pacientes hospitalizados com descrição de 
episódios de bacteremia, evidenciou-se que aqueles com tratamento préadmissional com estatina apresentaram menor taxa de mortalidade a longo $\operatorname{prazo}^{(64)}$.

É válido destacar que a LRA induzida por sepse apresenta diferenças importantes, em termos de características, respostas às intervenções e resultados clínicos, quando comparada à LRA não associada à sepse ${ }^{(56)}$. Estando a LRA associada a maiores índices de mortalidade neste caso, é de extrema importância saber identificar as alterações que caracterizam seu quadro e compreender os mecanismos fisiopatológicos envolvidos nesse processo, a fim de amenizar os agravos dessa importante síndrome clínica.

Sumarizando, esse estudo destacou a vulnerabilidade do sistema renal frente às mudanças fisiopatológicas causadas pela sepse em modelo experimental animal. As alterações dos parâmetros fisiológicos como hipotermia, hiperglicemia e crescimento bacteriano em líquido peritoneal, caracterizaram a sepse de origem abdominal. Após 48 horas da indução à sepse os animais apresentaram declínio na TFG e aumento dos metabólitos oxidativos, sendo classificados nos estágio de maior gravidade da LRA com alta taxa de mortalidade. Apesar de não ter sido observada melhora dos parâmetros fisiológicos nos animais que receberam pré-condicionamento com sinvastatina, confirmou-se seu efeito protetor sobre a função renal, com elevação da TFG e redução dos metabólitos oxidativo, mesmo com manutenção do baixo fluxo urinário. Essa atenuação demonstrou impacto na classificação da LRA. Os animais tratados com sinvastatina vivenciaram menor gravidade da LRA, com consequente redução na taxa de mortalidade.

Os instrumentos de pesquisa que envolvem as investigações com modelos com animais tem como vantagem o isolamento de variáveis. Essa característica permite maior confiança nas relações de causa e efeito. Contudo, a sepse se caracteriza por um empreendimento sindrômico complexo que dificulta a investigação de mecanismos fisiopatológicos específicos e exigirá sempre a complementação de dados experimentais e clínicos para sua elucidação. 
Os estudos experimentais podem representar estratégias de avanço na pesquisa em enfermagem, por descrever estratégias terapêuticas, como a estatina nesse caso, que possam contribuir para o planejamento da assistência em pacientes com disfunção renal. 
Ud 6 CONCLUSÕES 


\section{CONCLUSÕES}

A técnica de LPC induziu um quadro de sepse com hipotermia, hiperglicemia e cultura do líquido peritoneal positiva.

* Os animais sepse apresentaram declínio do clearance de creatinina, com aumento da creatinina sérica e redução do fluxo urinário, caracterizando episódio de LRA oligúrica.

Os animais com LRA induzida por sepse demonstraram elevação da excreção de peróxidos e TBARS urinários.

Os animais sepse apresentaram maior gravidade da LRA, com alta taxa de mortalidade.

O pré-condicionamento com sinvastatina melhorou a função renal e reduziu a liberação de metabólitos oxidativos na urina em animais com LRA induzida por sepse, confirmando sua ação como antioxidante. Adicionalmente, esse grupo foi classificado com menor gravidade da LRA, com aumento da taxa de sobrevida. 


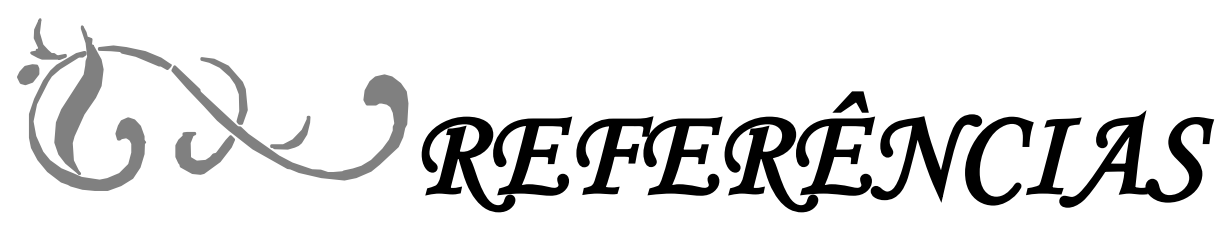




\section{REFERÊNCIAS}

1. Oppert M, Engel C, Brunkhorst FM, Bogatsch H, Reinhart K, Frei U, et al; German Competence Network Sepsis (Sepnet). Acute renal failure in patients with severe sepsis and septic shock - a significant independent risk factor for mortality: Results from the German Prevalence Study. Nephrol Dial Transplant. 2008; 23(3):904-9.

2. Angus DC, Linde-Zwirble WT, Lidicker J, Clermont G, Carcillo J, Pinsky MR. Epidemiology of severe sepsis in the United States: analysis of incidence, outcome, and associated costs of care. Crit Care Med. 2001; 29(7):1303-10.

3. Junior JALS, David CM, Hatum R, Souza PCSP, Japiassú A, Pinheiro CTS, et al. Sepse Brasil: estudo epidemiológico da sepse em unidades de terapia intensiva brasileiras. Rev Bras Ter Intensiva. 2006; 18(1):9-17.

4. Andrades ME, Morina A, Spasić S, Spasojević I. Bench-to-bedside review: sepsis-from the redox point of view. Crit Care. 2011; 15(5):230. Epub 2011 Sep 14.

5. White LE, Chaudhary R, Moore LJ, Moore FA, Hassoun HT. Surgical sepsis and organ crosstalk: the role of the kidney. J Surg Res. 2011; 167(2):306-15.

6. Dombrovskiy VY, Martin AA, Sunderram J, Paz HL. Rapid increase in hospitalization and mortality rates for severe sepsis in the United States a trend analysis from 1993 to 2003. Crit Care Med. 2007; 35(5):1244-50.

7. Chertow GM, Burdick E, Honour M, Bonventre JV, Bates DW. Acute kidney injury, mortality, length of stay, and costs in hospitalized patients. J Am Soc Nephrol. 2005; 16(11):3365-70.

8. Mehta RL, Kellum JA, Shah SV, Molitoris BA, Ronco C, Warnock DG, et al; Acute Kidney Injury Network. Acute Kidney Injury Network: report of an initiative to improve outcomes in acute kidney injury. Crit Care. 2007; 11(2):R31.

9. Doi K, Leelahavanichkul A, Yuen PST, Star RA. Animal models of sepsis and sepsis-induced kidney injury. J Clin Invest. 2009; 119(10):2868-78.

10. Chvojka J, Sýkora R, Karvunidis T, Radej J, Krouzecký A, Novák I, et al. New Developments in Septic Acute Kidney Injury. Physiol Res. 2010; 59(6):859-69. 
11.Zarjou A, Agarwal A. Sepsis and Acute Kidney Injury. J Am Soc Nephrol. 2011; 22(6):999-1006.

12. Dollins $M$, Kraus MA, Molitoris BA. Management of the patient witch renal failure. In: Brenner BM, editor. Brenner \& Rector's: The Kidney. Philadelphia: Saunders; 2004. p.2706-13.

13. Lerolle N, Nochy D, Guérot E, Bruneval P, Fagon JY, Diehl JL, et al. Histopathology of septic shock induced acute kidney injury: apoptosis and leukocytic infiltration. Intensive Care Med. 2010; 36(3): 471-8.

14. Nath KA, Norby SM. Reactive oxygen species and acute renal failure. Am J Med. 2000; 109(8):665-78.

15. Regueira T, Andresen M, Mercado M, Downey P. Physiopathology of acute renal failure during sepsis. Med Intensiva. 2011; 35(7):424-32.

16. Wang Z, Holthoff JH, Seely KA, Pathak E, Spencer HJ, Gokden N, et al. Development of oxidative stress in the peritubular capillary microenvironment mediates sepsis-induced renal microcirculatory failure and acute kidney injury. Am J Pathol. 2012; 180(2):505-16.

17. Bonventre JV, Yang L. Cellular pathophysiology of ischemic acute kidney injury. J Clin Invest. 2011; 121 (11):4210-21.

18. Dezoti CF, Watanabe M, Vattimo MFF. Heme oxygenase-1 role in the Polymyxin B induced Nephrotoxicity in rats. Antimicrob Agents Chemother. 2012; 56(10):5082-7.

19. Watanabe M, Neiva LBM, Santos CXC, Laurindo FRM, Vattimo MFF. Isoflavone and the heme oxygenase system in ischemic acute kidney injury in rats. Food Chem Toxicol. 2007; 45(12):2366-71.

20.Wang F, Li M, Cheng L, Zhang T, Hu J, Cao M, et al. Intervention with cilostazol attenuates renal inflammation in streptozotocin-induced diabetic rats. Life Sci. 2008; 83(25-26):828-35.

21. Soetikno V, Sari FR, Lakshmanan AP, Arumugam S, Harima M, Suzuki K, et al. Curcumin alleviates oxidative stress, inflammation, and renal fibrosis in remnant kidney through the Nrf2-keap1 pathway. Mol Nutr Food Res. 2013; 57(9):1649-59. Epub 2012 Nov 23.

22. Stolf AM, Livero RF, Dreifuss AA, Bastos-Pereira AL, Fabosi IA, Alves de Souza CE, et al. Effects of statins on liver cell function and inflammation in septic rats. J Surg Res. 2012; 178(2):888-97.

23. Kouroumichakis I, Papanas N, Proikaki S, Zarogoulidis P, Maltezos E. Statins in prevention and treatment of severe sepsis and septic shock. Eur J Intern Med. 2011; 2(2):125-33. 
24. Al-Otaibi KE, Al Elaiwi AM, Tariq M, Al-Asmari AK. Simvastatin attenuates contrast-induced nephropathy through modulation of oxidative stress, proinflammatory myeloperoxidase, and nitric oxide. Oxid Med Cell Longev. 2012; 831748. Epub 2012 Oct 10.

25. La Mura V, Pasarín M, Meireles CZ, Miquel R, Rodríguez-Vilarrupla A, Hide $D$, et al. Effects of simvastatin administration on rodents with lipopolysaccharide-induced liver microvascular dysfunction. Hepatology. 2013; 57(3):1172-81.

26.Zhang S, Luo L, Wang Y, Rahman M, Lepsenyi M, Syk I, et al. Simvastatin protects against $\mathrm{T}$ cell immune dysfunction in abdominal sepsis. Shock. 2012; 38(5):524-31.

27. Frey T, De Maio A. Incresead expression of CD14 in macrophages after inhibition of the colesterol biosynthetic pathway by lovastatin. Mol Med. 2007; 13(11-12):592-604.

28. Kruger P, Bailey M, Bellomo R, Cooper DJ, Harward M, Higgins A, et al. A multicenter randomized trial of atorvastatin therapy in intensive care patients with severe sepsis. Am J Respir Crit Care Med. 2013; 187(7):743-50.

29. Brasil. Ministério da Ciência e Tecnologia. Conselho Nacional de Controle de Experimentação Animal - Resolução normativa no 12 de 20 setembro de 2013. Institui a diretriz brasileira para o cuidado e utilização de animais para fins científicos e didáticos. Diário Oficial da União, Brasília, 25 set 2013. Seção 1: 52-9.

30. Ong PMP, Rodrigues LD. Seção de experimentação. In: Neves SMP, Mancini Filho J, Menezes EW, editores. Manual de Cuidados e Procedimentos com Animais de Laboratório do Biotério de Produção e Experimentação da FCF-IQ/USP. São Paulo: FCF-IQ/USP, 2013.p.91-154.

31. Monteiro R, Brandau R, Gomes WJ, Braile DM. Trends in animal experimentation. Rev Bras Cir Cardiovasc. 2009; 24(4):506-13.

32.Damy SB, Camargo RS, Chammas R, Figueiredo LFP. Aspectos fundamentais da experimentação animal - aplicações em cirurgia experimental. Rev Assoc Med Bras. 2013; 56(1):103-11.

33. Brasil. Ministério da Ciência e Tecnologia. Conselho Nacional de Controle de Experimentação Animal - Resolução normativa nำ13 de 20 setembro de 2013. Institui a diretriz da prática de eutanásia do Conselho Nacional de Controle de Experimentação Animal CONCEA. Diário Oficial da União, Brasília, 26 set 2013. Seção 1:5-12. 
34. Pinto CF, Watanabe M, Fonseca CD, Ogata CI, Vattimo MFF. A sepse como causa de lesão renal aguda modelo experimental. Rev Esc Enferm USP. 2012; 46(esp):86-90.

35. Luo X, Jian D, Lu Z. The beneficial effect of direct peritoneal resuscitation on septic shock in rats. J Biomed Biotechnol. 2011; 743763. Epub 2011 Nov 15.

36. Silva PL, Cruz FF, Fujisaki LC, Oliveira GP, Samary CS, Ornellas DS, et al. Hypervolemia induces and potentiates lung damage after recruitment maneuver in a model of sepsis-induced acute lung injury. Crit Care. 2010; 14(3):R114.

37. Teshima CAS, Watanabe M, Dezoti C, Nakamura SH, Vattimo MFF. Efeito renoprotetor da estatina: modelo animal de isquemiareperfusão em ratos. Rev Bras Ter Intensiva. 2010; 22(3):245-9.

38. Teshima CAS, Dezoti C, Watanabe M, Vattimo MFF. A estastina e a lesão renal aguda isquêmica em ratos. Acta Paul Enferm. 2012; 25(1):86-9.

39.Agência Nacional de Vigilância Sanitária. Farmacopéia Brasileira. Brasília: Agência Nacional de Vigilância Sanitária; 2010. Métodos biológicos, ensaios biológicos e microbiológicos. p.207-77.

40. Gay CA, Gebcki JM. Measurement of protein and lipid hydroperoxides in biological systems by the ferric-xylenol orange method. Anal Biochem. 2003; 315(1):29-35.

41. Halliwell B, Long LH, Yee TP, Lim S, Kelly R. Estabilishig biomarkers of oxidative stress: the mensurement of hydrogen peroxide in humam urine. Curr Med Chem. 2004; 11(9):1085-92.

42. Sihimizu MHM, Danilovic A, Andrade L, Volpi RA, Libório AB, Sanches $\mathrm{TRC}$, et al. $\mathrm{N}$-acetylcysteine protects against renal injury follwing bilateral ureteral obstruction. Nephrol Dial Transplant. 2008; 23(10):3067-73.

43. Peng ZY, Wang HZ, Srisawat N, Wen X, Rimmelé T, Bishop J, et al. Bactericidal antibiotics temporarily increase inflammation and worsen acute kidney injury in experimental sepsis. Crit Care Med. 2012; 40(2):538-43.

44. Pinto CF, Watanabe M, Neiva LBM, Vattimo MFF. Hydratation and Nacetylcisteine in acute renal failure caused by iodated contrast: an experiment in rats. J Nephrol. 2008; 21(5):783-8. 
45.Dyson A, Singer M. Animal models of sepsis: why does preclinical efficacy fail to translate to the clinical setting? Crit Care Med. 2009; 37(1Suppl):30-7.

46. Levy MM, Fink MP, Marshall JC, Abraham E, Angus D, Cook D, et al; SCCM/ESICM/ACCP/ATS/SIS. 2001 SCCM/ESICM/ACCP/ATS/SIS International Sepsis Definitions Conference. Crit Care Med. 2003; 31(4):1250-6.

47. Finfer S. Clinical controversies in the management of critically ill patients with severe sepsis: Resuscitation fluids and glucose control. Virulence. 2013; 4(8). Epub 2012 Aug 6.

48. Dellinger RP, Levy MM, Rhodes A, Annane D, Gerlach H, Opal SM, et al; Surviving Sepsis Campaign Guidelines Committee including the Pediatric Subgroup. Surviving sepsis campaign: international guidelines for management of severe sepsis and septic shock: 2012. Crit Care Med. 2013; 41(2):580-637.

49. Angus DC, Van der Poll T. Severe sepsis and septic shock. N Engl J Med. 2013; 369(9):840-51.

50.Paul M, Shani V, Muchtar E, Kariv G, Robenshtok E, Leibovici L. Systematic review and meta-analysis of the efficacy of appropriate empiric antibiotic therapy for sepsis. Antimicrob Agents Chemother. 2010; 54(11):4851-63.

51. Finfer S, Chittock DR, Su SY, Blair D, Foster D, Dhingra V, et al; NICE-SUGAR Study Investigators. Intensive versus conventional glucose control in critically ill patients. N Engl J Med. 2009; 360(13):1283-97.

52. American Diabetes Association. Standards of medical care in diabetes-2012. Diabetes Care. 2012; 35 (1):S11-63.

53. Bellomo R, Wan L, Langeberg C, May C. Septic acute kidney injury new concepts. Nephron Exp Nephrol. 2008; 109(4):e95-100.

54. Ritter C, Andrades M, Frota Júnior ML, Bonatto F, Pinho RA, Polydoro $\mathrm{M}$, et al. Oxidative parameters and mortality in sepsis induced by cecal ligation and perforation. Intensive Care Med. 2003; 29(10):1782-9.

55. Crimi E, Liguori A, Condorelli M, Cioffi M, Astuto M, Bontempo P, et al. The beneficial effects of antioxidant supplementation in enteral feeding in critically ill patients: a prospective, randomized, double-blind, placebo-controlled trial. Anesth Analg. 2004; 99(3):857-63. 
56. Liangos O, Wald R, O'Bell JW, Price L, Pereira BJ, Jaber BL. Epidemiology and outcomes of acute renal failure in hospitalized patients: a national survey. Clin J Am Soc Nephrol. 2006; 1(1):43-51.

57. Bellomo R, Ronco C, Kellum JA, Mehta RL, Palevsky P; Acute Dialysis Quality Initiative workgroup. Acute renal failure - definition, outcome measures, animal models, fluid therapy and information technology needs: the Second International Consensus Conference of the Acute Dialysis Quality Initiative (ADQI) Group. Crit Care. 2004; 8(4):R204-12.

58. Rosansky S, Glassock RJ, Clark WF. Early start of dialysis: a critical review. Clin J Am Soc Nephrol. 2011; 6(5):1222-8.

59. Thakar CV, Christianson A, Freyberg R, Almenoff $P$, Render ML. Incidence and outcomes of acute kidney injury in intensive care units: a Veterans Administration study. Crit Care Med. 2009; 37(9):2552-8.

60. Blanco-Colio LM, Tuñón J, Martín-Ventura JL, Egido J. Antiinflammatory and immunomodulatory effects of statins. Kidney Int. 2003; 63(1):12-23.

61. Almuti K, Rimawi R, Spevack D, Ostfeld RJ. Effects of statins beyond lipid lowering: potential for clinical benefits. Int J Cardiol. 2006; 109(1):7-15.

62. Işeri S, Ercan F, Gedik N, Yüksel M, Alican I. Simvastatin attenuates cisplatin-induced kidney and liver damage in rats. Toxicology. 2007; 230(2-3):256-64.

63.Dobesh PP, Klepser DG, McGuire TR, Morgan CW, Olsen KM. Reduction in mortality associated with statin therapy in patients with severe sepsis. Pharmacotherapy. 2009; 29(6):621-30.

64. Thomsen RW, Hundborg HH, Johnsen SP, Pedersen L, Sorensen HT, Schonheyder HC, et al. Statin use and mortality within 180 days after bacteremia: a population-based cohort study. Crit Care Med. 2006; 34(4):1080-6. 
Ud ANEXOS 


\section{Anexo A}

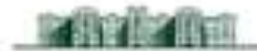 \\ MEDICINA \\ TSP \\ COMITÊ DE ÉTICA EM PESQUISA}

A CEUA do Comitê de Etica em Pesquisa da Faculdade de Medicina da Universidade de Sằo Paulo, em sessão de 23/10/2013, APROVOU o Protocolo de Pesquisa $\mathrm{n}^{0} \mathbf{3 7 8 / 1 3}$ intitulado: "EFETro DA ESTATINA EM MODELO EXPERIMENTAL DE LESÃO RENAL AGUDA INDUZIDA POR SEPSE" que utilizará 40 animais da espécie Ratos Wistar, apresentado pelo Departamento de NENHUM

Cabe ao pesquisador elaborar e apresentar ao CEP-FMUSP, o relatório final sobre a pesquisa, (Lei Procedimentos para o Uso Cientifico de Animais - Lei No $11.794-8$ de outubeo de 2008).

Pesquisador (a) Responsável: Maria de Fatima Fernandes Vattimo Pesquisador (a) Executante: Franciele Nascimento

CEP-FMUSP, 24 de Outubro de 2013.

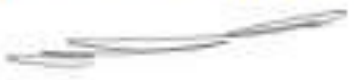

Dr. Eduardo Pompeu

Coordenador

Comissăo de Ética no Uso de Animaìs

$$
\text { 2Cheminn. }
$$

Prof. Dr. Roger Chammas Coordenador Comitê de Êtica em Pesquisa 